\title{
LITERACIDAD E IDENTIDADES EN LAS INVESTIGACIONES SOBRE FORMACIÓN DOCENTE EN BRASIL
}

\author{
LETRAMENTO E IDENTIDADES NAS PESQUISAS SOBRE FORMAÇÃo DOCENTE NO BRASIL
}

Literacy ANd IDENTITIES IN TEACHER'S EdUCATION RESEARCH IN BraZiL

\author{
Angela B. Kleiman \\ Ph. D. Lingüística, University of \\ Illinois at Urbana-Champaign, EE. UU. \\ Profesora titular, Departamento de \\ Lingüística Aplicada, Universidade \\ Estadual de Campinas (UNICAMP), \\ Brasil. \\ Calle Sérgio Buarque de Holanda, \\ N. ${ }^{\circ} 571$ - Ciudad Universitaria, \\ Campinas, SP, 13083-859, Brasil. \\ akleiman@mpc.com.br \\ https://orcid. \\ org/0000-0003-3536-3402
}

\begin{abstract}
RESUMEN
Este artículo se propone presentar algunos parámetros y principios utilizados en la elaboración de los programas de investigación realizados en Brasil desde 1991 por lingüistas aplicados, en la perspectiva teórica de los estudios de literacidad. Esta corriente se proponía contribuir a la transformación de estructuras educacionales elitistas y arcaicas (como, por ejemplo, los currículos de letras en la universidad brasileña). Uno de esos grupos pioneros fue Letramento do Professor, que aplicó el paradigma propuesto por Street (1984). Esta revisión también incluye nuevos estudios que se fueron adhiriendo a la vertiente sociocultural e histórica de los estudios de la literacidad. La fuente de estos trabajos fue el Diretório de Grupos de Pesquisa no Brasil Lattes, órgano del Conselho Nacional de Pesquisa (CNPq), que registra 512 grupos que investigan, o han investigado, la literacidad. En consonancia con la variedad de objetos de investigación dentro de los estudios de literacidad, a saber, relaciones entre literacidad y poder, efectos de las representaciones sobre la lengua escrita entre los grupos más vulnerables de la sociedad, en diversos escenarios, se presentan aquí las bases teóricas de dichas investigaciones, incluyendo teorías interaccionistas de lenguaje, estudios culturales, teorías decoloniales y estudios de literacidad, con enfoques metodológicos en los cuales coexisten diversas prácticas interpretativas.
\end{abstract}

Palabras claves: literacidad; identidad; poder; prácticas de literacidad.

\section{RESUMO}

Este artigo tem como objetivo apresentar alguns parâmetros e princípios utilizados na elaboração dos programas de pesquisa realizados no Brasil desde 1991 por linguistas aplicados usando a perspectiva teórica dos estudos do letramento. Essa perspectiva visava contribuir para a transformação de estruturas educacionais elitistas e arcaicas (como, por exemplo, os currículos de Letras na universidade brasileira). Um desses grupos pioneiros foi o Letramento do Professor, que pesquisava o letramento baseado no novo paradigma proposto por Street (1984). Essa revisão examina ainda os novos estudos que foram se aderindo à vertente sociocultural e histórica dos estudos do letramento. A principal fonte de informação para esses trabalhos foi o Diretório de Grupos de Pesquisa no Brasil Lattes, órgão do Conselho Nacional de Pesquisa (CNPq), que registra 512 grupos que pesquisam, ou pesquisaram, o letramento. Em consonância com a variedade de objetos de pesquisa nos estudos de letramento, tais como as relações entre letramento e poder, efeitos das representações sobre a língua escrita nos grupos mais vulneráveis da sociedade,

Recibido: 2018-09-29 / Aceptado: 2019-01-28 / Publicado: 2019-05-20

DoI: 10.17533/udea.ikala.v24n02a11 
em diversos cenários, também se apresentam aqui as bases teóricas das pesquisas, que incluem teorias interacionistas de linguagem, estudos culturais, teorias decoloniais e estudos de letramento, com enfoques metodológicos nos quais coexistem diversas práticas interpretativas.

Palavras-chave: letramento; identidade; poder; práticas de letramento.

\section{Abstract}

This paper intends to account for several criteria and principles guiding the creation of research programs carried out in Brazil from 1991 on, by researchers in the field of applied linguistics in the literacy studies approach. This approach aimed to help transform out-of-date and elitist structures in Education (like, for example, language curricula at Brazilian higher education). One of those pioneering groups was Letramento do Professor, which applied Street's new paradigm (1984). This review also looks at new studies that gradually began adhering to the sociocultural and historic trend of literacy studies. Our main source of information to access those works was Lattes Brazil's Research Group Directory, an agency under the umbrella of the National Research Council (CNPq), which has 512 research groups registered, which are doing or have done research on literacy. In line with the varied research subjects in literacy studies, namely relations between literacy and power, effects of representations on written language among the most vulnerable social groups, in different settings, the theoretical grounds of those research works are examined here, including interactionist theories of language, cultural studies, decolonial theories, and literacy studies, with methodological approaches gathering together varied interpretative practices.

Keywords: literacy; identity; power; literacy practices. 


\section{Introducción}

Un país de dimensiones continentales incapaz de atender a las exigencias educacionales contemporáneas tiene problemas también de magnitud continental. Ese es el caso de Brasil, cuyos gobernantes intentan, sucesivamente, desde la década de 1990, por medio de decretos, leyes y reglamentos, subsanar el acceso desigual y precario a la escuela de la gran mayoría de los brasileros. El proceso legislativo más reciente para regular la educación en el país se inició con la promulgación de la Ley de Directrices y Bases de 1996, en la que se establecía que, hasta 2006, todos los profesores de educación básica debían recibir capacitación docente de nivel superior. Fue así como se lanzó un gran proyecto de capacitación de profesores con larga trayectoria en la actividad docente, cuya formación más alta era de nivel medio. Posteriormente, se reglamentaron los currículos para la formación de profesores de educación básica mediante las directrices curriculares nacionales para los cursos de licenciatura, lo que implicó, en muchos casos, un proceso de reestructuración de los programas de licenciatura.

Desde otro frente, por esa misma época, se dio inicio a un proyecto de orientación curricular a nivel nacional, con el objetivo de establecer las metas educacionales de la nación, que debían orientar las propuestas curriculares de estados y municipios para cada disciplina. ${ }^{1}$ Para la enseñanza de la lengua materna, que será el foco de este artículo, las propuestas sobre el papel se fundamentaron en una concepción de aprendizaje de la lengua como un proceso sociocultural e histórico que brinda herramientas para representar y significar el mundo y a la persona misma (Brasil, 1997). Hoy, poco más

1 Con objetivos semejantes, pero para otros segmentos educacionales fueron publicados también: Directriz Curricular Nacional para la Educación Infantil (1998b), Directrices Nacionales para la Enseñanza Media (1998c), Directriz curricular nacional para las escuelas indígenas (1998d), Directriz para la formación de profesores (1999a), Parámetros en acción (1999b, 2000), Directrices para la formación de profesores indígenas (2002a); Propuesta curricular para la educación de jóvenes y adultos (2002b). de una veintena de años después, está en proceso de implementación la Base Nacional Común Curricular, un documento que determina los conocimientos esenciales que deben haber recibido todos los alumnos a lo largo de los nueve años que dura el ciclo de educación básica. Este documento debe seguirse a la hora de elaborar e implementar los currículos de las redes públicas y particulares de enseñanza del país (Brasil, 2018). Un documento similar para el nivel medio de enseñanza está en vías de votación y adopción.

Si en el panorama amplio de los cambios educacionales parece que se han dado grandes pasos en políticas educativas en pro de una educación más equitativa y orgánica, que respete la diversidad en sus manifestaciones sociales, regionales y étnico-culturales, una breve mirada a las correspondencias que tendrían que converger en la escuela constituye evidencia de la enorme distancia entre el papel y la práctica, entre el proyecto y su implementación. En el nivel del microanálisis, las cuestiones educacionales que exigen respuestas por parte de los formadores, técnicos y políticos continúan obstaculizando el trabajo del profesor y el aprendizaje de los educandos.

Entre el conjunto de acciones a nivel macro del Ministerio de Educación (MEC), generalmente ideadas por técnicos y académicos del área de educación de la federación, y el conjunto de acciones delineadas por un equipo de profesionales en la escuela, según las orientaciones de equipos de coordinación pedagógica del municipio o del estado, existe una brecha que muchas veces influye en lo que ocurre en ambos. Aquí se ubican las investigaciones sobre la literacidad, ${ }^{2}$ cuyas contribuciones y resultados se discutirán en este trabajo.

En las secciones que siguen a esta introducción, presentaremos cuestiones relativas a la literacidad

2 Usamos el vocablo literacidad sabiendo que no hay consenso sobre ese uso en los países de habla hispana, según nos dice Zavala: "mientras que estudiosos en el Brasil han logrado consolidar el neologismo letramento para llenar un vacío semántico, en los países de habla hispana todavía no se ha llegado a ningún consenso" (2002, p. 17). 
y la formación del profesor, divididas en cuatro aspectos que no son necesariamente secuenciales a pesar de que las implicaciones o conclusiones del tema que se investigó primero tuvieron influencia en la emergencia de un nuevo tema de investigación, y así sucesivamente. En la primera sección, "Oralidad letrada, legitimización y legitimidad", presentamos un panorama de las relaciones establecidas entre los nuevos estudios de literacidad (New Literacy Studies) y los estudios sobre la escritura en el contexto latinoamericano, que confluyeron para delinear un cuerpo de investigaciones sobre los efectos de la escritura en millones de analfabetos en Brasil durante la década de los 90. En el apartado "Identidades y docencia", discutimos investigaciones que examinan posicionamientos identitarios de educadores populares que ejercen el oficio de alfabetizadores sin una formación profesional específica, y los de profesoras alfabetizadoras con formación en programas de pedagogía de nivel universitario. La comparación de las identidades lectora/no lectora asumidas por los alfabetizadores en los dos grupos aclaran algunas cuestiones sobre la interdependencia entre literacidad y poder, que son relevantes para la formación de los profesores en cuyas manos está el aprendizaje de prácticas letradas para la vida social.

En la sección "Agentes, profesores y artefactos culturales", examinamos diversas propuestas de investigadores, que tienen como objetivo resignificar la enseñanza de la lengua oral y escrita. Se toma como base para esta agrupación la noción de Bartlett (2007), quien investigó en profundidad las prácticas de literacidad de un estado nordestino de Brasil, indagando si los artefactos culturales son los objetos involucrados en la atribución colectiva de significados, razón por la cual son los propulsores de la producción y reproducción de significados e identidades. Los trabajos discutidos en esta sección se realizan en espacios en los que las prácticas de lenguaje de profesores, educandos, y otros agentes son considerados subalternos en relación con las prácticas hegemónicas. En un conjunto de trabajos se desarrollaron e implementaron proyectos de literacidad, que se diferencian principalmente por su carácter situado y su enraizamiento en la práctica social. También incluimos un proyecto de producción de entradas lexicográficas, que entendemos como un modelo formador inventado ante la dificultad de la cultura letrada para dar nombres a otros mundos, como, por ejemplo, una región del mundo del nordeste de Brasil. En esa categoría también hemos incluido los estudios que analizan prácticas de literacidad no legitimadas, consideradas periféricas o en las márgenes del centro del poder, los modelos de relacionamiento y de representación de la lengua escrita que ofrezcan indicios para la creación de modelos didácticos prometedores.

En la cuarta parte, "La formación revisitada: prácticas de literacidad académica", discutimos la cuestión de la formación del profesor a partir de la óptica del sujeto más vulnerable en la situación de enseñanza y aprendizaje. Partimos de los primeros trabajos del grupo Letramento do Profesor hasta llegar a los trabajos de nuevos grupos que se derivaron de aquel. En ellos se ha constituido un nuevo objeto de investigación, las prácticas académicas de la literacidad con los concomitantes problemas que ellas ocasionan a poblaciones que no las conocen, como es el caso de los alumnos negros, pobres o indígenas admitidos a través de programas de acción afirmativa, particularmente debido a valoraciones extravagantes sobre la neutralidad u objetividad de esas prácticas. Para terminar, en "Una palabra final", presentamos nuestras consideraciones finales.

Las investigaciones seleccionadas representan los trabajos más significativos en el campo de la lingüística aplicada, si se considera la producción científica y la formación de nuevos investigadores. Para realizar la selección, se consultó la base de datos denominada Diretório de Grupos de Pesquisa no Brasil Lattes, órgano del Conselho Nacional de Pesquisa (CNPq), en el que aparecen 512 grupos $^{3}$ que investigan, o han investigado, sobre literacidad. De esos, escogimos los grupos que pertenecían

330 grupos estaban inactivos, no actualizados o en vías de actualización; más de 70 no tenían una descripción de las investigaciones que desarrollaban. 
a las áreas de lingüística y lingüística aplicada. En la selección final, todas las investigaciones examinadas en este artículo fueron realizadas bajo la égida de la lingüística aplicada: su selección tiene límite y contrapunto en los estudios sobre literacidad y formación del profesor desarrollados en los campos de la educación y la pedagogía. Para este corte epistemológico, fueron considerados los aportes metodológicos y analíticos interdisciplinares que conforman los panoramas investigativos de la literacidad procedentes del dialogismo y otras teorías interaccionistas del lenguaje, del análisis de la interacción, de los estudios culturales y de teorías decoloniales del saber (Moita Lopes, 2013; Kleiman y Assis, 2016). Los enfoques metodológicos utilizados para la obtención de los datos son interpretativos con una fuerte orientación etnográfica, los que, basándose en la observación de quehaceres cotidianos relevantes y en el análisis de las prácticas de uso del lenguaje, buscan entender el papel de la literacidad en la vida social contemporánea.

\section{Oralidad letrada, legitimización y legitimidad}

El uruguayo Ángel Rama y el brasileño Paulo Freire influenciaron la recepción en el país de las teorías sobre literacidad (letramento en Brasil) planteadas por Street (1984) y Heath (1983), e introducidas por Kleiman (1995) en el ambiente académico brasileño en la década de 1990. Por la misma época, tenían lugar grandes esfuerzos por establecer una política educacional más inclusiva y global, consonante con las necesidades de actuación en el mundo social del egresado. Rama (1985), al desenmascarar la relación histórica entre la letra y los procedimientos reguladores de la sociedad latinoamericana, y Freire (1970, 1980), al unir la alfabetización de adultos analfabetos pobres y excluidos de la escuela al proceso de concientización sobre sus propias condiciones materiales, ya marcaban un camino contrario al de aquellas teorías que postulaban la superioridad y neutralidad cultural de la lengua escrita (y de su enseñanza en la escuela) hasta entonces dominantes (véase Goody, 1977 y Goody y Watt, 1972), y validadas por la gran mayoría de los estudiosos de la lengua escrita. El modelo que cuestionó esa neutralidad (Street, 1984) es considerado, por eso, una ruptura paradigmática con estudios anteriores (cf. Gee, 1986).

Brasil es una sociedad que, en plena década de 1990, contaba con cerca de 20 millones de analfabetos, ${ }^{4}$ muchos de quienes vivían en calidad de inmigrantes en la ciudad "letrada", "modernizada", "politizada", que describe Ángel Rama, una ciudad que hoy consideraríamos "globalizada" (Perus, 2005, p. 364). En este escenario, el impacto de la lectura y la escritura fue observado en los grandes programas gubernamentales para la erradicación del analfabetismo que venían siendo impulsados por el gobierno, desde la década de 1970. Sin embargo, no habían obtenido resultados significativos para la disminución del contingente de analfabetos (siempre bordeando los veinte millones de habitantes). Esos programas no movilizaban ningún sentido crítico que mitigara los efectos de la pobreza y la desigualdad, características de la vida social de los jóvenes y adultos matriculados en los cursos ofrecidos por diversas campañas nacionales de alfabetización. ${ }^{5}$ Mediante el nuevo paradigma sobre la escritura como una práctica social, que postulaba el concepto de intrincadas y múltiples interrelaciones entre la escritura y la situación sociocultural e histórica, era posible entender cómo la lectura y la escritura escolar podían constituir barreras insuperables para el aprendizaje y, en consecuencia, para la transformación de grupos sociales al margen de la sociedad letrada, detentadora del poder hegemónico.

Las comunidades brasileñas al margen de las prácticas sociales que se concretan por intermedio del uso

4 Correspondiente a $19,7 \%$ de la población con quince años o más. Según datos del Instituto Brasilero de Geografía y Estadística (IBGE), las tasas de analfabetismo han disminuido significativamente en las dos últimas décadas, excepto en el grupo de los más avanzados en edad. Investigación Nacional por Muestra de Domicilios Continua (PNAD continua, por sus siglas en portugués).

5 Como la ambiciosa campaña de la dictadura militar en la década de los 70, conocida como Mobral (Menezes y Santos, 2001). 
de la lengua escrita no tenían, como en muchas de las comunidades estudiadas por Street (1984, 1995), una historia de escrituras alternativas a aquellas enseñadas en la escuela. Debemos a la investigación de Scribner y Cole (1981) el conocimiento sobre el caso tal vez más conocido: el de la comunidad Vai en Liberia, que manejaba tres tipos distintos de sistemas escriturales: el código alfabético de origen latino de la lengua inglesa para aprender las disciplinas escolares, el código árabe para asuntos religiosos y un sistema silábico, o silabario Vai, para transacciones familiares y comerciales.

Constatada esa diferencia, una de las primeras cuestiones investigadas por lingüistas aplicados en Brasil, usando el sistema conceptual de los 'estudios de literacidad', fue la siguiente: ante la ausencia de códigos vernáculos, que ya nacen inextricablemente enmarañados en la situación comunicativa, y que por eso mismo liberan al sujeto de la carga que implica el aprender la lectura y la escritura y sus usos en situaciones desvinculadas de los asuntos de lo cotidiano de la vida social ¿qué hacen los adultos brasileños no escolarizados para actuar en la ciudad letrada?

Con la intención de dar respuesta a esa pregunta, una de nuestras primeras investigaciones partió de la observación de estudiantes en clases de educación para jóvenes y adultos (EJA), cuyas profesoras participaban de un proyecto de formación de docentes alfabetizadores de adultos, actividad que fue encomendada por el acalde de una pequeña municipalidad del interior del estado de São Paulo (registrada en Kleiman, 1995). Los adultos en los que se centró la investigación ejercían cargos de representación política en sindicatos y asociaciones de base, o eran representantes electos para ejercer la función de ediles en pequeños municipios del estado. Llamó nuestra atención que ellos exhibían una relación diferenciada con el discurso oral, pues se habían apropiado de expresiones y vocablos comúnmente usados por escolarizados y de uso más común en la lengua escrita. La investigación de I. Pereira (1997) sobre la oralidad letrada de esos grupos trae muchas evidencias de que esos representantes eran usuarios eficientes de géneros escritos, pues redactaban, por ejemplo, complejas misivas de reivindicación de derechos y de salarios en nombre de los trabajadores a quienes representaban, dictándolas a secretarias que actuaban como sus escribas, quienes solamente transcribían al código alfabético escrito los textos dictados según las normas exigidas por el género y, por la variante estándar del idioma.

Las prácticas de estos sujetos ejemplifican, dentro del discurso de la cotidianidad, las posibilidades transgresivas de la oralidad, y podrían ser consideradas, según Kuhnheim (2014, p. 8), artefactos culturales híbridos que funcionan como testigos de contextos culturales mutantes. Los discursos de esos sujetos exhiben una marcada tensión entre el discurso oral y el discurso escrito, proveniente de una paradójica desconfianza en la palabra escrita, y a la vez un 'carácter profundamente letrado', a pesar de los altos índices de analfabetismo, pues serían sociedades 'fundadas sobre una utilización persuasiva de la escritura, así como sobre un profundo respeto por ella' (González, apud Kuhnheim, 2014, p.8).

En esa dirección, el siguiente testimonio de uno de los representantes del sindicato de conductores de autobuses, entrevistado por Pereira (1997), revela ejemplarmente una paradoja en las palabras del sujeto politizado, pero poco escolarizado:

Cuando nadie aplaude uno se siente con tres palabras, uno habla y piensa estoy diciendo estupideces y ahí se desequilibra totalmente y luego piensa yo no tengo estudio qué estoy haciendo aquí.... y ahí sube otra persona que tiene estudio pero que está hablando puras tonteras y es aplaudida. ¿ Por qué? Porque tiene expresión para poder hablar. (p. 164)

6 En el original portugués: “... quando não tem aplauso você se sente com três palavras você já fala você pensa eu tô falando já tô falando besteira então ai vem aquela coisa de você realmente cai aí de quatro porque ... você logo pensa pô eu num tenho estudo porque que eu tô falando aqui aí chega sobe uma outra pessoa que tem o estudo às vezes tá falando uma puta babaqueira é aplaudida, por 
El líder sindical entrevistado, que se está alfabetizando, establece un vínculo entre "el estudio", o sea, el saber formalmente adquirido y legitimado por una institución, y el efecto retórico que arranca aplausos, que él atribuye a ese estudio. Pereira (1997, p. 188) argumenta que el análisis de la oralidad letrada muestra que, para los sujetos no escolarizados y en militancia política, el factor crucial en el desarrollo de una práctica discursiva marcada por la escritura es la relación que estos sujetos establecen con el lenguaje; por medio de este crean un sentido de trabajo colectivo de un grupo que respalda las prácticas discursivas de sus integrantes.

En el otro grupo investigado en ese mismo proyecto de la década de los noventa, formado por las profesoras de esos estudiantes no alfabetizados (Oliveira, C., 1994), conseguimos más evidencias de comportamientos letrados de las profesoras, también inextricablemente anclados en la situación comunicativa: una de las profesoras más entusiastas, que era también poeta y escribía mucho, declaraba su encanto por los sonidos, rimas y aliteraciones de la poesía que leía y escribía, pero no lograba, en su papel de profesora, superar los dictámenes de la 'didáctica' de la ortografía, lo que no le permitía aceptar como correctas las respuestas de sus alumnos, que daban como palabras que rimaban aquellas palabras homófonas (que terminaban con un mismo sonido; /u/, por ejemplo, que tenían más de una grafía - [u] y [l]—, como [meu] y [mel]: o sea, casos de pronunciación idéntica, y, por lo tanto, $\operatorname{rimada}(/ \mathrm{meu} / \mathrm{y} / \mathrm{meu} /)$, pero con dos posibles formas de deletrear el sonido $/ \mathrm{u} /$ en posición final de sílaba. ${ }^{7}$

La concepción de la literacidad como conjunto de prácticas que utilizan la lengua escrita marcó la preferencia por esa denominación, la más utilizada por el grupo de investigación Literacidad del Profesor $^{8}$ desde sus inicios (1991), sobre otros nom-

que? Porque ele tem expressão pra poder falar”. Esta y las demás traducciones son de la autora de este trabajo.

7 Con los significados: mí, mío y miel, respectivamente.

8 Letramento do Professor, hoy en red con la Universidad Estadual de Campinas (UNICAMP), la Universidad Ca- bres también usados en Brasil como letramentos, multiletramentos, letramentos múltiplos.9 Como destaca Matencio, al describir la perspectiva de las investigaciones que tratan de avistar, captar y comprender (2009, p. 5) las actividades de lectura y de escritura que son parte de prácticas sociales, "la contribución determinante de los estudios sobre la literacidad es resultado de la suposición de que se lidia, siempre, con prácticas -en plural": ${ }^{10}$

si las prácticas de literacidad son situaciones en las que un "artefacto" escrito es esencial para la interacción, porque integra la propia naturaleza de la interlocución y del proceso de producción de sentido, ellas implican tanto lo que se hace cuando se lee y se produce texto, como las concepciones que les son subyacentes y los modelos sociocognitivos que subyacen a esas representaciones, dándoles significado. (Matencio, 2009, p. 8) $)^{11}$

El concepto de prácticas letradas permite entender no solamente el carácter situado del uso de la lectura y escritura, sino también la existencia

tólica de Minas Gerais (PUC, Minas), la Universidad Federal de São Carlos (UfSCAR), la Universidad de Taubaté (Unitau), la Universidad do Estado da Bahía (UNEB), la Universidad Federal do Rio Grande do Norte (UfRN) y la Universidad Federal da Paraíba (UfpB).

9 La expresión multiletramentos surgió originalmente para indicar que las prácticas de literacidad están, cada vez más, imbricadas con otros sistemas semióticos: espaciales, gestuales, auditivos, como son típicamente las prácticas digitales (Cope y Kalantzis, 2009). Consideramos que los demás aspectos que, según Rojo (2009, pp. 108-109), justificarían la terminología - las diferentes esferas en que circulan las prácticas y el hecho de que esas prácticas son culturales (habiendo muchas culturas son multiculturales) - ya hacen parte de la definición de prácticas de literacidad.

10 En el original: "a contribuição determinante dos estudos sobre o letramento resulta de assumirem que se lida, sempre, com práticas - no plural".

11 Original: "se as práticas de letramento são situações em que um "artefato" escrito é essencial para a interação, porque integra a própria natureza da interlocução e do processo de produção de sentido, elas implicam tanto o que se faz quando se lê e se produz texto, quanto as concepções que lhes são subjacentes e os modelos sócio-cognitivos que subjazem a essas representações, dando-lhes significado". 
de prácticas que atraviesan contextos, que son transferibles, generalmente, de un contexto más legitimado, como el escolar, a otro considerado menos legítimo, como el de la recreación (como escribir poesía en los momentos de ocio). Estas prácticas serían calificadas, usando la terminología de Brandt y Clinton (2002), como transcontextualizadas y transcontextualizadoras, en la medida en que permiten la transferencia de prácticas sociales relacionadas con la lectura y escritura de un contexto a otro, como las prácticas escolares, que no solo consideran las condiciones locales donde se realizan, sino que también incorporan elementos de prácticas globales más estrechamente vinculadas a las relaciones de poder.

Sin embargo, la vía de adopción de prácticas de una esfera de actividades a otra no es unilateral, y puede perjudicar el progreso de los procesos de alfabetización y literacidad, particularmente cuando las prácticas de la institución dominante son impuestas a la fuerza sobre grupos que no están politizados y cuya resistencia, por eso mismo, no llega a constituirse en estrategia ${ }^{12}$ para subvertir las prácticas de la institución más poderosa. Tomemos como ejemplo la investigación de Descardesi (1992), que describe una situación de prueba realizada en la ciudad de Cosmópolis, en

12 Tomamos el concepto de estrategia del sociólogo de lo cotidiano, Michel de Certeau (1994), que la define en oposición al concepto de táctica. Las estrategias son producidas y usadas por poderes institucionalmente constituidos, que pueden variar desde una pequeña asociación de barrio, una secretaría estatal de educación, determinando las relaciones entre la institución y los otros de afuera. Los que no pertenecen a la institución, pero están bajo su poder, desarrollan tácticas para poder lidiar con ella. Un importante corolario de esta distinción es que el sujeto que pertenece a algún grupo institucionalizado, sea religioso, político o profesional puede, en vez de usar tácticas personales, defensivas, no planeadas, al lidiar con las dificultades, obstáculos o reglas burocráticas de una institución, usar las estrategias de su grupo para no ser subyugado, para posicionarse y apropiarse del poder, aunque sea momentáneamente, y así subvertir las relaciones estratégicas definidas por la institución más poderosa. el estado de São Paulo, para satisfacer las exigencias de una nueva ley, promulgada en 1990. En dicha ley se le exigía a todo funcionario municipal -inclusive a quienes realizaban trabajos manuales como barrenderos de calles, recolectores de basura, aseadores de edificios públicos- comprobar que era capaz de leer y escribir, además de demostrar que poseía conocimientos de lengua portuguesa y de matemática. ${ }^{13} \mathrm{La}$ única forma de mantenerse en el trabajo era presentar la prueba, para comprobar esos diversos saberes. Muchos de esos trabajadores eran analfabetos; dado que los trabajos que tenían que desempeñar eran los más bajos desde el punto de vista de la remuneración y del prestigio social, nadie con un poco más de escolaridad se habría prestado a hacerlos.

Para una persona analfabeta, o con baja escolaridad (por ejemplo, hasta el tercer año de educación básica primaria), el código alfabético, las clasificaciones gramaticales básicas, y hasta el género examen escrito son desconocidos, sin contar con que solucionar un problema escrito de suma, resta, multiplicación o división es muy diferente de saber sumar, restar, multiplicar y dividir. En medio de una situación de sobrevivencia personal y familiar como esta, los trabajadores crearon tácticas para responder las preguntas de la prueba: los supervisores e inspectores de sala leían las preguntas y las alternativas de respuesta a cada persona, y marcaban en la hoja de respuestas del examen la escogida por el examinado. Se trata, claramente, de una táctica sin planeación, inventada para ese momento adverso, en la cual el sujeto ni siquiera tenía condiciones u oportunidades de demostrar todo lo que sabía, ya que dependía, entre muchos otros factores, de la buena voluntad del examinador para anotar la respuesta y llevar a buen término la interacción. Una estrategia de negociación de las condiciones para hacer la prueba entre el empleador (el municipio) y el trabajador (representado por su sindicato) se constituiría en una estrategia entre dos grupos menos asimétricos en su relación

13 Conocimientos escolares, a juzgar por las preguntas que debían responder. 
de fuerzas, y haría el examen menos agresivo, tenso y humillante para el trabajador.

El interés de los investigadores por los diferentes modos de usar la lengua escrita, en los diferentes textos producidos, en los diversos modos de leer y de pensar sobre la escritura de acuerdo con la situación de comunicación en el tiempo y el espacio, compatible con el concepto de prácticas letradas, hizo aumentar el número de trabajos que focalizaban las manifestaciones de carácter social, colectivo y, a menudo, cooperativo de ellas en prácticamente todas las instituciones; la excepción es la escuela, donde las prácticas desarrolladas enfatizan el carácter individual de la adquisición de la lengua escrita, como en el proceso de alfabetización, cuyas prácticas son indiferenciadas en relación con la situación y, en gran medida, al tiempo y espacios en que ocurren. Esas investigaciones, conocidas como la vertiente sociocultural e histórica de los estudios de literacidad se apoyan en contribuciones etnográficas, discursivas e históricas y presuponen que las prácticas de literacidad son constituidas situadamente por sujetos que interactúan en instituciones mediante prácticas sociales en las cuales suelen reproducirse relaciones de identidad y de poder.

Con base en la constitución del objeto de investigación, un segundo concepto de literacidad emerge en la investigación brasileña. En este enfoque más individual, en contraste con el de carácter social, se define la literacidad como estado o condición adquirida por un grupo social o por un individuo como consecuencia de haberse apropiado de la escritura, según la definición de la investigadora del área educacional Magda Soares (1998). Esa diferencia de enfoque entre práctica social, movediza y mutante como todo proceso social, de vertiente sociocultural, adoptada por lingüistas aplicados, y la condición ya alcanzada, tiene importantes consecuencias teórico-metodológicas, según la evaluación de Tinoco (2008), porque la segunda presupone saberes, actitudes y comportamientos de los grupos letrados, que pueden ser examinados, medidos y clasificados. Según Tinoco, la definición de literacidad como estado o condición
se ajusta bien a la concepción de literacidad escolar como algo que puede ser mesurado por parámetros predefinidos para cada año, nivel o grado de escola- ridad. Ya al focalizar las 'prácticas sociales' o, en otras palabras, 'el proceso de literacidad', se amplía el radio de acción de la literacidad en el tiempo y el espacio. Pasa a ser vislumbrado como un fenómeno que nos acompaña por toda la vida y en las más diferentes esfe- ras de actividad (no apenas en la escuela) con los más diferentes propósitos y formas de inserción y de parti- cipación. (Tinoco, 2008, p. 106) $)^{14}$

Nuestro contexto de actuación nos permitió comprobar repetidamente que los usos de la lectura y la escritura difieren según la institución o la esfera de actividad $^{15}$ (escolar, de trabajo, religiosa, doméstica, entre otras), según la situación y el contexto (Street, 1984; Barton y Hamilton, 1998), y según objetivos y modos de participación. El carácter situado de las prácticas de literacidad permite considerar, en la investigación, los procesos que un sujeto adopta para ser legitimado como persona letrada, en el contexto de determinada interacción. Esos procesos involucran capacidades que van más allá del dominio de un código, tales como reconocer cuáles son las prácticas legítimas en determinada situación y ajustar su propio discurso al hablar, interpretar, leer, para participar en la situación como miembro legítimo del grupo. Desde el punto de vista metodológico, el foco en la construcción situada de esa

14 "se adéqua bem à concepção de letramento escolar como algo que pode ser mensurado por parâmetros predefinidos para cada série, nível ou grau de escolaridade. Já ao focalizar as 'práticas sociais' ou, em outras palavras, 'o processo de letramento', alarga-se o raio de ação do letramento em tempo e espaço. Passa-se a vislumbrá-lo como um fenômeno que nos acompanha por toda a vida e nas mais diferentes esferas de atividade (não apenas na escola) com os mais diferentes propósitos e formas de inserção e de participação".

15 Por esferas de la actividad humana entendemos los contextos sociales de usos del lenguaje, que contemplan la situación específica y el tiempo histórico. Cada esfera determina los géneros que circulan en ella y sus modos de producción y recepción (Bakhtin, 1990). 
legitimidad como 'alfabetizado', o 'letrado’ impulsó la investigación de contextos en los que se construía, paso a paso, esa tentativa de legitimización, con mayor o menor éxito, en, y a través de la interacción (Kleiman, 1998).

Las observaciones y resultados en esta primera etapa de la investigación sobre literacidad, en una década en que el modelo paradigmático de antropólogos como Street y Heath era aún poco conocido, contribuyeron a cambiar algunas representaciones sobre la lengua escrita de la profesora alfabetizadora basadas en "mitos de la literacidad" (cf. Graff, 1995 [1979]) muy enraizados que "explicarían" el analfabetismo histórico de las poblaciones pobres, negras, indígenas, y sus causas. Se comprobaba, en el microanálisis de la interacción por el lenguaje, que los macroprocesos sociales resultantes en preconcepto y estigma (Goffman, 1963) que afectan a los grupos históricamente excluidos de la escuela, ${ }^{16}$ se (re)construyen paso a paso en el diálogo con el otro (Erickson y Schultz, 1981). La perspectiva resultante de ese foco en esa (re)construcción de (i) representaciones sobre el mundo y sobre sí mismo, (ii) de las relaciones sociales (iii) y de identidades (de género, letrada/no letrada, profesional) por, con y en el lenguaje, aportan un nuevo modo, lingüístico y discursivo, de contemplar fenómenos ya estudiados por sociólogos, antropólogos e historiadores (Freire, 1989; Ribeiro, 1995; Bourdieu, 1993[1983]; Certeau, 1994, Lahire, 2001).

\section{Identidades y docencia}

La docencia en educación básica en Brasil, hoy en día desempeñada casi exclusivamente por mujeres está, desde hace tiempo, cultural y socialmente desvalorizada. Mientras más bajo el nivel escolar, más mujeres ocupan cargos de poquísimo prestigio social, muy mal remuneradosy predominantemente

16 Aquellos que incorporaron el estigma de "sujeto menor", según analiza Ratto (1995) en una propaganda sobre el analfabeto, que estaría históricamente determinado e inherente al sistema que regula las relaciones de poder entre letrados e iletrados" (p. 267). destinados a las clases populares. En esa jerarquía, la desvalorización ha sido mayor en el caso de las alfabetizadoras - profesoras que están habilitadas para enseñar los primeros cinco años de la educación básica - quienes han sido descritas en la literatura como lectoras restringidas o impedidas ${ }^{17}$ (Britto, 1998), pues proceden de un estrato social bajo, con familias con poca o ninguna escolaridad, y aunque el título de profesora representa un claro caso de ascenso social gracias al estudio, la introducción tardía a la cultura escrita les roba la seguridad de 'sentirse' letradas y perturba la percepción de sí mismas como miembros legítimos de los grupos letrados a quienes representan en la institución escolar (Batista, 1998).

Consideraciones como esas, comunes en la universidad y en la prensa, pierden su aparente objetividad cuando son analizadas desde la nueva perspectiva de los usos de la escritura, que proponen los estudios de la literacidad. Dichos estudios nos obligan a considerar prácticas contextualmente situadas, tales como las prácticas de leer y escribir para el trabajo y en la situación de trabajo, las cuales por lo mismo consideran exigencias y capacidades de comunicación efectivamente requeridas para la profesión. ${ }^{18}$ Desde esa perspectiva, nos parece que la profesora está entablando un diálogo extremamente desigual con estas poderosas instituciones que la responsabilizaban principalmente por los pésimos resultados de la educación pública en nuestro país, como lo evidencian los exámenes estandarizados de portugués y matemática. Esa situación la transforma, para los efectos de nuestra

17 "Leitora interditada" en el original en portugués.

18 La necesidad de redefinir los programas y currículos de formación de profesores parecía, y continúa pareciendo, ineludible; sin embargo, su fundamento en el análisis de las prácticas de uso de la lengua escrita en la esfera profesional local de trabajo, tomando en consideración que las exigencias de comunicación en la sala de clase son un enfoque original que todavía se topa con incontables obstáculos debidos a la estructura arcaica y elitista de la mayoría de los cursos de pedagogía y de letras en el país, que forman, respectivamente, los profesores de los primeros años y los profesores de lengua portuguesa. 
investigación sobre la letra y el poder, en un sujeto más vulnerable, al actuar en las márgenes de las instituciones poderosas.

Con la meta de contribuir a la renovación de la representación social de las alfabetizadoras, se intentó conocer las identidades lectoras de estas en diferentes contextos, por medio de métodos cualitativos, tales como la obtención de sus historias orales en el proceso de formación inicial en el servicio (Guedes Pinto, 2002; 2005), o de protocolos de lectura con profesoras de los años iniciales compartiendo oralmente la lectura de documentos normativos de la profesión (Borges da Silva, 2003; 2006), o de etnografías de los encuentros de formación entre la investigadora-formadora y alfabetizadoras populares (Vóvio, 2007a; 2007b). Las investigaciones evidencian los errores de las concepciones esencialistas del proceso formativo de estas agentes y la necesidad de reconocerlas en su diversidad cultural, con patrimonios culturales diversos, lo que nos lleva a concluir que "el conjunto de experiencias y trayectorias formativas y el modo como dan significado a la lectura se constituyen en el punto de partida para formular programas y procesos formativos que se dispongan a favor de los sujetos y su desarrollo" (Vóvio, 2007a, p. 253). ${ }^{19}$

Una pregunta surge al considerar esa perspectiva: ¿cómo revertir una situación que es, a fin de cuentas, consecuencia de la formación por la cual la universidad es responsable?

La búsqueda de una respuesta a ese interrogante abre dos posibles caminos de investigación: como objeto de investigación de la escritura académica, o sea, una línea de investigación ya contemplada por los NEL en los países de habla anglosajona (Lea y Street, 1998; Lillis y Scott, 2007) y, en países hispanohablantes, por Zavala (2010) o, como

19 En el original: "o conjunto de experiências e trajetórias formativas e do modo como a significam a leitura constituem-se em ponto de partida para formular programas e processos formativos que se coloquem a favor dos sujeitos e seu desenvolvimento". una cuestión de identidad, objeto de los estudios culturales, que necesitaría la apertura de una nueva línea de investigación, no (necesariamente) relacionada con binomios conceptuales como identidad y género, identidad y sexualidad, identidad y etnicidad, identidad y lengua, entre otros, sino relacionada con la proletarización de la clase profesional docente en el contexto brasileño, abrazando binomios como identidad y clase, identidad y profesión, identidad y literacidad.

La perspectiva crítica de la formación de profesores, a fin de problematizar las concepciones "heredadas" 20 sobre la identidad letrada de ese profesional, se apoya en la concepción de identidad de los estudios culturales, un constructo flexible, múltiple, y cambiante. ${ }^{21}$ Ya en los años de la década de los 90, el concepto de identidad se instauraba centralmente en la vertiente sociocultural de los estudios de literacidad, en la misma definición del concepto: "un conjunto de prácticas sociales cuyos modos específicos de funcionamiento tienen implicaciones importantes para las formas en que los sujetos involucrados en esas prácticas construyen relaciones de identidad y de poder" (Kleiman, 1995, p. 11). ${ }^{22}$ Desde esa perspectiva teórica, la profesora puede, en la interacción, subvertir normas y reglas, reinventar representaciones de sí misma, y asumir identidades que la posicionen favorablemente en la situación, intentando, no siempre con éxito, fortalecerse en relación al otro y sobreponerse a las jerarquías de desigualdad propias de las categorías binarias que se le aplican

20 Usamos la terminología usada por Freitas (2018, p. 26) para referirse a conceptos y prácticas hegemónicas sustentadas en hipótesis modernistas y coloniales, pues compartimos con él la necesidad de afirmación de puntos de vista decoloniales en los países de Latinoamérica (cf. Kleiman, 2013).

21 Según Hall (1998) serían identidades dislocadas y fragmentadas, debido a la cantidad de cambios estructurales de las sociedades e la posmodernidad.

22 Original: "um conjunto de práticas sociais cujos modos específicos de funcionamento têm implicações importantes para as formas pelas quais os sujeitos envolvidos nessas práticas constroem relações de identidade e de poder”. 
en su calidad de profesora, mujer y, generalmente, de clase social baja, a saber: buena-mala profesora, lectora-no lectora, letrada-no letrada, entre otras.

La inestabilidad, fluidez y movilidad de las categorías identitarias postuladas para describir al sujeto posmoderno que participa en la práctica social le permitirían, en principio, asumir una postura de contestación y resistencia. Sin embargo, nuestros datos no muestran ni cuestionamiento ni ruptura frente a las representaciones desfavorables y las valoraciones peyorativas sobre sus identidades profesionales entre las alfabetizadoras participantes de las investigaciones que habían pasado, o estaban pasando, por un proceso de formación en la universidad. Por el contrario, su discurso se caracteriza por la ausencia de protagonismo, la expresión de impotencia generalizada y confusión: se autodenominan malas profesoras (sin tiempo para planificar sus clases), lectoras de desempeño bajo (los quehaceres profesionales y los quehaceres domésticos les exigían todo el tiempo disponible), sin control sobre el propio proceso de formación. Todas esas identificaciones están sugeridas en el siguiente fragmento sobre la selección y realización de lecturas de una profesora en formación inicial en una universidad prestigiosa. El pasaje fue tomado del testimonio de una alfabetizadora con años de actuación en la escuela, quien estaba cursando pedagogía para satisfacer las nuevas políticas gubernamentales sobre formación docente a fin de poder continuar enseñando en la escuela. Aquí se refiere a una de las disciplinas que está estudiando, y afirma que le gusta mucho:

comenzamos con la Ilíada, que yo había comprado para leer /.../ la comencé a leer, pero no la acabé, entonces pasamos a Platón, yo no pude comprar el libro porque no lo encontré, comencé a leerlo cuando lo pedí prestado, no terminé porque ahí él [el docente universitario] ya pasó al próximo tema y yo no pude terminarlo. Pasamos a Dom Casmurro, que también lo había comprado para leer, leí la mitad cuando cambió el tema y yo dejé la mitad sin leer, dije no, más adelante termino $^{23}$

23 Banco de datos del grupo Letramento do Professor. En el original: "a gente começou com a Ilíada, que eu tinha
Considerando ese marco, entendemos mejor la declaración de Borges da Silva (2003), ${ }^{24}$ quien en su tesis doctoral se plantea entre sus objetivos contribuir a la transformación de la representación de la profesora como profesional poco competente, especialmente la profesora alfabetizadora de los primeros años escolares. En el trabajo de Borges da Silva, hay una tendencia a fortalecer al profesor en el tema escogido, tema que continúa en sus líneas de investigación posteriores, en las autoetnografías de las profesoras, cuyos trabajos orienta, muchas de ellas sobrevivientes del sistema universitario que, según relatan, nunca las legitimó (cf. Borges da Silva, 2001, $2005,2016)$. Con base en este método, proveniente de los estudios socioculturales, esas docentes pueden resignificar sus experiencias personales en el contexto de las prácticas de literacidad en la esfera familiar, escolar y académica para entender aspectos de sus prácticas en la esfera profesional.

En marcado contraste entre las autoevaluaciones de las alfabetizadoras, que ya concluyeron o están por concluir un curso superior, encontramos las palabras de las alfabetizadoras populares, sin curso formal de magisterio o pedagogía para su actuación en la docencia, que participan de las ruedas de conversación que hacían parte del proceso de formación ofrecido por una organización no gubernamental, en la cual la formadora ejerció también el papel de investigadora (Vóvio, 2007a). Las palabras de las educadoras populares ocupan un lugar diametralmente opuesto en el eje de los sentidos producidos en el discurso,

comprado pra ler... /.../ aí eu comecei a ler, mas não acabei, aí a gente foi pra Platão, eu não consegui comprar o livro porque eu não achei, comecei a ler, que eu peguei emprestado, não terminei porque aí ele já foi pra próxima aula e eu não consegui terminar. Fomos pra Don Casmurro, que eu também tinha comprado pra ler, eu li metade e já mudou de aula e eu guardei a metade sem ler, falei não, mais pra frente eu termino".

24 Fue una de las investigadoras del grupo Letramento do Professor antes de sus varios desdoblamientos, Borges da Silva coordina hoy el grupo Núcleo de Estudos de Linguagens e Tecnologias (NELT), con sede en la Universidad Federal de Bahia (UFBA). 
y así, las identidades que ahí se construyen, en el continuo intercambio de significaciones y sentidos negociados en el diálogo, se polarizan en relación con las identidades reproducidas por las profesoras alumnas del curso universitario. En ese estudio, así como la investigadora alterna sus posiciones, los alfabetizadores populares alternan las suyas en la rueda, asumiendo posiciones como sujetos de investigación hasta estudiantes. De ese modo, establecen conexiones más cercanas o más distantes entre ellos, a partir del foco de sus enunciados, que puede recaer en la diferencia o en la identificación que construyen, aproximándose o distanciándose de la formadora y de los demás colegas educadores.

En los movimientos de aproximación, que eran la mayoría, se construían a través del discurso, como educadores y lectores legítimos. Según Vóvio (2007a) hubo una "construcción colectiva de las versiones de los educadores-participantes sobre sí mismos y sobre sus historias de lectores y de sus posicionamientos sobre el acto de leer y sobre la enseñanza de la lectura"(p. 124), ${ }^{25}$ lo que sugiere fuertemente la formación de una red, o comunidad de lectores: se declaran agentes de lectura de libros y otros materiales, sujetos activos que eligen, rechazan, abandonan o recomiendan libros, sujetos cognoscentes que conocen sus preferencias y sus modos de leer, que se representan y se presentan a los otros como lectores críticos, curiosos, voraces, selectivos, en fin, que se autolegitiman como lectores responsables de introducir a otros al mundo escrito.

Constataciones como esas era común encontrarlas en otros contextos y situaciones de comunicación en las cuales la profesora reproducía jerarquías evaluativas en relación con lo que puede o no puede leerse, con lo que es lectura legítima, siguiendo cánones de otras instituciones, como la académica

25 Original: "construção coletiva de versões dos educadores-participantes sobre si mesmos e sobre suas histórias de leitores e de posicionamentos sobre o ato de ler e sobre o ensino da leitura". o la literaria. En el estudio colaborativo con profesoras de un barrio ribereño del Estado de Pará, en la Amazonia brasileña, quienes participaban de un proyecto coordinado por la investigadora Correa (2010), se fundamenta en las valoraciones despreciativas que las profesoras atribuían a sus lecturas para considerarlas tránsfugas ${ }^{26}$ de clase, a pesar de haber sido orientadas desde la infancia, por sus grupos de origen no escolarizados o con poca escolaridad, a no reproducir la condición social de los padres y abuelos, trabajadores manuales y domésticos de bajos ingresos; ellas consiguen la movilidad social pretendida pero no (sienten que) alcancen la condición de representantes de la sociedad letrada.

Al contrario de grupos como el de las alfabetizadoras populares — quienes aprovechan las oportunidades de formación para fortalecerse mutuamente en su calidad de miembros de una misma clase, trabajando por y para otras personas de su clase-, en la poderosa institución universitaria las profesoras no encontraron oportunidades de identificarse como miembros de un grupo con afinidades que, colectivamente, podría constituir un lugar configurado como espacio estratégico —en el sentido postulado por Certeau (1994) de resistencia, que desestabilice identidades y desfavorezca la (re)producción de relaciones de desigualdad y dependencia, y que los lleve a consolidar el proceso de construcción de identidades profesionales, de clase o de género. En ese sentido, la calificación sociológica-psicológica de

26 El concepto de tránsfugas de clase de Lahire (2001) se refiere a aquellas personas que salieron de sus condiciones sociales de origen por la vía escolar y son producto de "una clara oposición entre dos grandes matrices de socialización contradictorias (el universo familiar y el universo escolar), cuyos valores simbólicos son socialmente diferentes en el marco de una sociedad jerarquizada (prestigioso/desvalorizado; alto/bajo; dominador/dominado...) que lleva la heterogeneidad de los hábitos, de los esquemas de acción incorporados a organizarse bajo la forma de un clivaje del yo, de un conflicto interno central que organiza (y avergüenza) cada momento de la existencia." (pp. 53-54). 
Lahire (2001) sobre las tránsfugas de clase puede ser parcialmente apropiada, pues las profesoras pasan "permanentemente, durante su travesía en el espacio social, de una situación de coexistencia pacífica de los hábitos incorporados a una situación conflictual" (Lahire, 2001, p. 55). ${ }^{27}$ Como Bartlett (2007, p. 54) nos recuerda, "solo con parecer [letrado] no es suficiente. La persona también debe aprender a "sentirse" letrada para poder realizar literacidad". 28

\section{Agentes, profesores y sus artefactos culturales}

Al comparar los grupos de alfabetizadoras en cursos de formación y en servicio activo en una gran universidad pública, con alfabetizadores de asociaciones y barrios sin formación específica, se percibe que las identidades de lector, construidas en el diálogo no pueden ser adjudicadas, totalmente, ni a la escolaridad ni al ejercicio de una profesión en cuya realización representan a los grupos letrados. Más bien, la investigación indica la absoluta necesidad de abandonar la asimetría profesor universitario-alfabetizadora-alumna, que favorece la ocupación de posiciones subalternas sobre las prácticas de literacidad y de incentivar la construcción de prácticas a partir de los propios lugares e identidades del alumno o participante más vulnerable de la situación. Varios investigadores intentan hacer eso desde una perspectiva sociocultural de la literacidad, por medio de artefactos culturales en consonancia con esa perspectiva. De ellos nos ocuparemos en esta sección.

Desde una perspectiva sociocultural del análisis del mundo social, son relevantes los significados

27 En portugués: "Os trânsfugas passam, de facto, permanentemente, durante a sua travessia do espaço social, de uma situação de coexistência pacífica dos hábitos incorporados a uma situação conflitual".

28 En el original: “'seeming' alone is not sufficient. One must also learn to 'feel' literate in order to do literacy." que un determinado objeto adquiere, como sugieren Bartlett y Holland, inspiradas en Vygotsky (Bartlett y Holland, 2002). En las prácticas de literacidad en la sala de clase, esos artefactos abarcan desde el pizarrón, el libro didáctico, las notas, una frase como “imuy bien!”, los géneros, hasta los modelos didácticos utilizados, lo que nos interesa discutir. Según las autoras, "los artefactos son construcciones sociales o productos de la actividad humana que pueden transformarse en herramientas utilizadas en los procesos de producción cultural" (Bartlett y Holland, 2002, p. 13). ${ }^{29}$ Adicionando una perspectiva discursiva e interaccionista, los artefactos culturales son colectivamente producidos en y a través del lenguaje durante la interacción entre los agentes ${ }^{30}$ de un evento letrado (Heath, 1983), es decir, en una situación comunicativa en la cual la lengua escrita tiene un papel central en la producción y recepción de significados y en la construcción de sentidos.

En un contexto de formación de profesores en el nordeste de Brasil, —región que presenta los segundos peores resultados en relación con todo índice de tipo educacional (la peor es la región norte)—, Tinoco (2008) $)^{31}$ desarrolló un modelo de enseñanza y aprendizaje con los

29 En el original: "Artifacts are social constructions or products of human activity and they in turn may become tools engaged in processes of cultural production."

30 El concepto de agente social ha sido relevante para describir las acciones diferenciadas de los participantes de un evento de literacidad, según Kleiman (2006).

31 El Grupo de investigación a que Tinoco pertenece (Letramento e Etnografia, con sede en la Universidade Federal del Rio grande del Norte (UfRN) es uno de los más activos y representativos en el desarrollo de 'proyectos de literacidad'. Además de los investigadores de la UFRn, como Oliveira, (Santos) Marques, participa de esa red de investigación D. Kersch, de la Universidad Federal de Rio Grande do Sul (Ufrgs), del Grupo de Investigación Formação de professores, multiletramentos e identidades - con sede en la Universidad Unisinos que también fomenta, junto con la investigación, el desarrollo de proyectos didácticos de género en contrapunto a proyectos de literacidad (Kersch y Guimarães, 2012). 
profesores-alumnos con curso secundario completo, en formación inicial en la universidad y con amplios años de actuación en clases de portugués en secundaria. Este modelo se estructura alrededor de la práctica social en conformidad con los principios que sustentan la concepción de literacidad. Combinando la investigaciónacción con una etnografía de las actividades en la disciplina de práctica profesional o docente (estágio supervisionado), un requisito para los cursos de licenciatura, que también era obligatoria para estos profesores a pesar de su experiencia docente, Tinoco definió objetivos y métodos que propiciaran la búsqueda de formas conductivas al cambio en los modelos para enseñar y aprender a leer y escribir textos en las escuelas. Para eso introdujo a sus alumnos, los profesores en formación, a la pedagogía de proyectos y, específicamente, a los proyectos de literacidad. ${ }^{32}$ Estos profesoresalumnos, a su vez, desarrollaron proyectos de literacidad con sus alumnos en las escuelas donde continuaban ejerciendo su profesión, que estarían vinculados a prácticas en que la lectura y la escritura son herramientas para la acción social, favorecen el aprendizaje significativo a través de la colaboración mutua, de la negociación de responsabilidades y del consecuente reposicionamiento

32 Kleiman (2000) los define como un conjunto de actividades que nace de un interés real en la vida de los alumnos, cuya realización requiere usar la lengua escrita, o sea, la lectura de textos que, de hecho, circulan en la sociedad y la producción de textos que serán leídos, en un trabajo colectivo de alumnos y profesor, cada uno según su capacidad. El proyecto de literacidad es una práctica social en la cual la escritura es utilizada para alcanzar alguna finalidad que ultrapasa el aprender a leer y escribir por aprender. (p. 238)

En el original: "um conjunto de atividades que se origina de um interesse real na vida dos alunos e cuja realização envolve o uso da escrita, isto é, a leitura de textos que, de fato, circulam na sociedade e a produção de textos que serão lidos, em um trabalho coletivo de alunos e professor, cada um segundo sua capacidade. $\mathrm{O}$ projeto de letramento é uma prática social em que a escrita é utilizada para atingir algum outro fim, que vai além da mera aprendizagem da escrita”. identitario de estudiantes, profesores y demás participantes (Tinoco, 2008, p. 176). ${ }^{33}$

Otros estudiosos (Cunha, 2010a; 2010b; Cunha, Kleiman y Tinoco, 2013; Oliveira, Tinoco y Santos, 2011; Santos, 2012; Oliveira, M. S. y Santos, 2012; Marques, 2016) organizaron proyectos de literacidad junto con profesores en diversas modalidades de formación docente..$^{34}$ Estos son modelos didácticos con actividades organizadas según el principio de la primacía de la práctica social. En ellos, el conocimiento de contenidos (habilidades, procedimientos, comportamientos, conceptos lingüísticos, géneros del discurso), que ya han sido elementos estructuradores del currículo en diversas propuestas, se convierten en elementos-medio, pues se entiende que, si bien estos permiten la participación en la práctica social, su introducción y enseñanza sistemática debe resultar de la necesidad de usarlos para la acción social, determinada por el deseo del alumno de solucionar un problema específico de su realidad local.

Pensar en términos de proyectos implica, por ejemplo, que antes de seleccionar una lista de habilidades, o géneros, o procedimientos, relevantes para la enseñanza de determinado objeto de conocimiento, se hace necesario planear con los alumnos un conjunto de actividades que les sean relevantes para algún fin que les interesa, sea en la vida escolar

33 En el original: "Vinculados a práticas em que a leitura e a escrita são ferramentas para agir socialmente, eles favorecem a aprendizagem significativa por meio da colaboração mútua, da negociação de responsabilidades e do consequente reposicionamento identitário de estudantes, professores e demais participantes".

34 Los proyectos de Santos y de (Santos) Marques fueron implementados en cursos técnicos y profesionales para estudiantes de secundaria, dentro de la modalidad de Educación para Jóvenes y Adultos (EJA), o sea, para estudiantes que, por diversas razones no pudieron terminar el curso básico o el curso secundario en la edad prevista. Un objetivo general de sus proyectos ha sido la oferta de disciplinas cuyos contenidos no se restrinjan ni a factores económicos ni a las demandas del mercado de trabajo, comprometiéndose más con la formación general humanística del estudiante. 
o fuera de la escuela. Con ese punto de partida, se desarrollan actividades (orientadas por el profesor o por alumnos con el saber necesario) que demandan conocimientos especificados en el currículo; estos son responsabilidad del profesor.

Por ejemplo, en la propuesta de la Base Nacional Común Curricular (Brasil, 2017) se especifica que cuando el objeto de conocimiento es el texto argumentativo, una de las habilidades que debe aprenderse en el 9. ${ }^{\circ}$ año para alcanzar ese objetivo es "Producir texto argumentativo, asumiendo una postura frente a un tema polémico, argumentando de acuerdo con la estructura propia de ese tipo de texto y utilizando diferentes tipos de argumentos —de autoridad, comprobación, ejemplificación" (Brasil, 2017, p. 147). ${ }^{35}$ Junto con la habilidad para escribir textos correctamente siguiendo la norma estándar, y el uso de recursos expresivos adecuados al género, la citada es la habilidad procurada en el eje relacionado con escritura y producción textual.

Las habilidades serán otras en el eje de la oralidad o la lectura (Brasil, 2017, pp. 142-147).

Para tornar realidad esa orientación (o exigencia) curricular en la implementación de esos objetivos en la escuela — -según defienden los defensores de los proyectos de literacidad - no es necesario fragmentar las habilidades por ejes de prácticas, y mucho menos seguir el orden sugerido: del objeto de conocimiento a la habilidad involucrada en ese conocimiento para después determinar las actividades que propiciarían su aprendizaje. Más bien, el movimiento se concretiza en dirección inversa cuando se parte de la práctica social, pues esta dictamina cuáles son las actividades que viabilizan la práctica, los procedimientos que precisan seguirse, los géneros que se requiere movilizar, para poner en marcha los textos leídos, escritos o hablados, así como las habilidades que deben ser aprendidas

35 En el original: "Produzir texto argumentativo, assumindo posição diante de tema polêmico, argumentando de acordo com a estrutura própria desse tipo de texto e utilizando diferentes tipos de argumentos - de autoridade, comprovação, exemplificação". para que su invención y uso haga alguna diferencia en el tejido social.

En una colaboración para la formación de las profesoras de portugués en una escuela de enseñanza fundamental y media del interior de São Paulo, Cunha (2010a, 2010b) y las profesoras de portugués que con ella colaboraban iniciaron la realización de un proyecto, cuya planificación se inició al escuchar los alumnos de la clase a fin de saber lo que los movía a la acción. Se identificó que lo que los preocupaba e indignaba en ese momento era un reglamento sobre vestuario masculino escolar, recién implantado por la dirección de la escuela. A partir de ese hallazgo, fueron orientando las clases para un objetivo que les interesaba: hacer conocer la opinión de ellos sobre esa cuestión y convencer a la dirección de la escuela de cambiar la regulación. El sistema periodístico se prestaba mucho más que el escolar para la amplia divulgación del polémico tema, y, por eso, el proyecto culminó con la producción del primer número de un periódico escolar, en el cual los debates y textos tantas veces reescritos en el aula se transformaron en un editorial (lleno de argumentos bien fundamentados), en entrevistas con el equipo gestor de la escuela y con alumnos y alumnas, en subtítulos de fotos pertinentes al asunto, en titulares de noticias, etc. En el ejemplo, el movimiento didáctico-pedagógico pasa de la práctica social al 'contenido' que se va a movilizar para poder participar de la situación, nunca lo contrario.

Parte de los conflictos identitarios que aquejan al profesor tienen sus raíces, no en los procesos de socialización de la infancia - en la familia y en la escuela, discutidos en la sección anterior- sino en la total falta de estructura para dar una clase en un panorama de negligencia y abandono, entre los peores del mundo. ${ }^{36}$ La riqueza está tan alta-

36 Por ejemplo, de acuerdo con los últimos índices de la Organización para la Cooperación y Desarrollo Económico (Better Life Index, OCDE, 2018), en Brasil, solamente el 49\% de los adultos entre 25 y 64 años de 
mente concentrada en la región sudeste del país y hay todavía, en este vasto país, tantas culturas desconocidas, o representadas solamente a través de toscos estereotipos, que los alumnos de las regiones más remotas son alfabetizados con palabras desconocidas, como en una lengua extranjera, por intermedio de palabras que nunca oyeron pronunciar, que denotan objetos que nunca olieron, palparon, vieron o saborearon.

Teniendo en cuenta que la región semiárida del nordeste brasilero produce riquezas, saberes y conocimientos, y con el deseo de dar a conocer esa cultura y, de paso, intentar facilitar el diálogo entre el 'sertão'37 de Bahía y el resto de Brasil, Cosme Santos (2016) realizó estudios sobre la identidad cultural de la región 'sertaneja', utilizando como índice de las manifestaciones de la cultura e identidad regional lo que el léxico de la región revelaba. Las palabras seleccionadas se organizaron en diversos artefactos culturales para la escuela, como glosarios, diccionarios y entradas digitales. Esos compendios revelarían, según Santos, no solamente la identidad cultural del grupo social que usaba las palabras allí registradas, sino también la identidad cognitiva y sociolingüística de los habitantes de la región, así como las condiciones sociales e históricas de sus usos de la lengua.

edad ha terminado la educación media superior, cifra mucho menor que el promedio mundial de $74 \%$. El país de la OCDE con el segundo menor rendimiento educativo es Brasil (solamente Sudáfrica es peor), con una calificación media de 395 puntos, lo que significa que una brecha de 136 puntos separa al joven brasileño medio del alumno japonés medio, cuyo rendimiento lo coloca en el extremo superior de la escala de rendimiento, con un promedio de 529 puntos. Tristemente, en promedio, en todos los países de la OCDE existe una gran diferencia en las calificaciones entre los estudiantes del nivel socioeconómico más alto y los del más bajo. Recuperado de: https://read.oecd-ilibrary.org/education/ education-at-a-glance-2018/brazil_eag-2018-73-en\#

37 Región semiárida del Nordeste brasileño, con temperaturas típicamente tropicales, y longos períodos de sequía. En el imaginario brasileño el "sertão" representa el espacio vasto, desconocido, alejado de las ciudades.
De esa investigación (Santos y Lima, 2013; Santos, 2016), en la cual colaboraron profesores en formación y sus alumnos, resultó no solamente un registro escrito de la memoria lexical del grupo social; el método lexicográfico situado fue también el propulsor de una demanda real de literacidad por parte de educadores, estudiantes y habitantes del sertón semiárido, quienes, mediante ese trabajo de selección, registro y archivo, se convirtieron en protectores de su lengua y del acervo lexical regional. Para Santos, llevar a la escuela la lexicografía trae importantes implicaciones para la literacidad de profesores y alumnos, porque la historia constata que el proceso de elaboración de diccionarios es una de las marcas visibles del proceso de legitimación por vía de la escritura de una variedad lingüística o de una lengua.

Otras investigaciones con grupos considerados al margen de los centros productores de saber o detentores del poder, como los estudios con quilombolas y rappers realizados por Sito (2010) y de Souza (2009), respectivamente, con mujeres de edad avanzada que regresan a la escuela (Pereira, A. de S., 2009; 2013; 2014), con narradoras de historias que no saben leer ni escribir (Tfouni, 1988 $)^{38}$ pueden ser todos caracterizados como trabajos que examinan espacios de resistencia y de

38 Tfouni investigó en su tesis doctoral el discurso de narradoras de historias que no sabían leer ni escribir y examinó las transformaciones discursivas realizadas por narradoras analfabetas cuando tratan de solucionar las tareas de categorización que ella les propuso con base en el enfoque metodológico de Luria (1976). Concluye que las hipótesis sobre diferencias cognitivas entre alfabetizado y no alfabetizado son insustentables si se consideran las prácticas discursivas, que revelan la capacidad de esas narradoras de estructurar el propio discurso para conferirle una aparente unidad. Sin embargo, nuestra opción por trabajos en el área de lingüística aplicada, con orientación antropológica y etnográfica excluye trabajos posteriores de la autora y de miembros de su grupo, sobre el proceso de autoría sustentados teóricamente por el análisis de discurso y el psicoanálisis. Por otro lado, se incluyeron trabajos de investigadores que dictan cursos de pedagogía y educación, quienes comparten los marcos teóricos y metodológicos ya descritos, como es el caso del grupo coordinado por Guedes Pinto, por ejemplo. 
articulación de estrategias en prácticas que favorecen la invención de nuevos repertorios, acervos y artefactos para sus cotidianas interacciones con el otro que determina la norma y que, en vez de posicionarse como lo diferente en lo identitario, lo cultural, lo epistemológico, se quiere posicionar como superior.

Sito (2010) describe y analiza ${ }^{39}$ varias prácticas de literacidad en una comunidad quilombola del litoral del sur de Brasil durante el período en que, para tener acceso al título de propiedad de sus tierras, los moradores de esa comunidad tuvieron que establecer diálogo con agentes del estado en situaciones de uso burocrático de la lengua escrita, envolviendo nuevas prácticas de uso de esa modalidad, desconocidas por el grupo hasta ese momento. La historia de luchas de esa comunidad negra para legalizar sus tierras hace necesario repensar la escritura instrumental, generalmente ofrecida por instituciones como la universidad, a grupos tradicionalmente excluidos de la escuela y del mundo letrado, de modo que se incluyeran otros textos, otros géneros, ${ }^{40}$ otras prácticas, en fin, todo lo que hiciera avanzar la lucha por la tierra. ${ }^{41}$

En el análisis de las interacciones entre el equipo de liderazgo comunitario y los burócratas de 'la ciudad letrada' (Rama, 1985), se visualiza el potencial de los movimientos populares organizados como 'agencias de literacidad' (Kleiman, 1995), más relevantes que las agencias tradicionales para pensar los procesos de implantación de políticas afirmativas para poblaciones negras en esos contextos.

39 Como en la mayoría de las investigaciones de vertiente sociocultural, Sito hizo una inmersión en las comunidades quilombolas de la región, participando de proyectos para la formación de equipos de liderazgo y para la implantación de asociaciones comunitarias, exigidas por ley para ser reconocidas como interlocutores del gobierno federal.

40 Como las actas, rendición de cuentas, presupuestos, informe, entre otros, además del muy discutible análisis técnico socioantropológico, analizados por Sito (2010).

41 Que en el caso específico del estudio de Sito ya era legalmente de ellos, según testamento en posesión de los líderes de la comunidad.
Más importante todavía, por su potencial de empoderamiento, concomitante al proceso de desarrollo de una identidad letrada, se observa la emergencia de una identidad relacionada a la lucha contra el racismo que, en el caso de esta comunidad, en que la participación en la lucha política es muy reciente, consiste en reconocerse como quilombola.

Souza (2009, 2011) llega a verificaciones del mismo tenor al describir y analizar la actuación de jóvenes rappers que se constituyen en agentes de literacidad por intermedio de las manifestaciones de la cultura hip-hop, en las cuales siempre están presentes biografías de personajes históricos, letras de música, libros, revistas, fanzines, con los cuales se promueve la adquisición de conocimientos en las comunidades donde actúan dando shows de rap y de reggae, participando en debates y charlas, con muestras de videos, eventos musicales, saraos de poesía, grupos de estudio, rueda y clases de capoeira, lanzamientos de libros, periódicos y revistas, cuyo planeamiento propicia enriquecedoras oportunidades para concretar la práctica social letrada: selección, negociación y solicitación del local; programación de fechas y horarios; invitación o convocatoria de miembros, elaboración de pautas, informes sobre las actividades y tomas de decisión. Si las actividades son demoradas y dispendiosas, las metas son mucho más ambiciosas, como por ejemplo la difusión de valores para fundamentar prácticas letradas por medio de acciones educativas que informan y movilizan a la acción solidaria por mejoras locales de las comunidades donde actúan y viven. Como agentes de literacidad del movimiento hip hop hacen surgir prácticas consideradas por Souza como prácticas letradas de reexistencia, ${ }^{42}$ por lo que revelan en relación con la lucha social que los jóvenes libran cotidianamente.

Otros frentes de investigación ${ }^{43}$ también contribuyen de modos muy interesantes a repensar

42 Juego de palabras con el concepto de resistencia.

43 Pensamos, por ejemplo, en los trabajos sobre realizados en Brasilia y Goiás por estudiantes que realizan su 
y surear $^{44}$ los preconceptos sobre las prácticas de literacidad en las periferias, asumiéndolas como tácticas, quizá estrategias (Certeau, 1994), equivalentes a "trincheras desde donde se puede luchar contra la dominación blanca y el capital, siendo menos víctima y con más dignidad”. ${ }^{45} \mathrm{El}$ análisis de Freitas (2018) sobre literacidad del profesor, fundamentado en presupuestos de las teorías queer - que estudian prácticas sociales de uso de la lengua que cuestionan dicotomías sobre el cuerpo, la sexualidad, el género-, tiene en común con las investigaciones aquí descritas una meta de ruptura con estándares grafocéntricos y coloniales sobre normalidad, subalternidad y legitimidad de la producción del saber.

En la misma línea, A. de S. Pereira ${ }^{46}$ (2014) realiza una etnografía de la cotidianidad de un grupo de mujeres que nacieron en una época en la que pocos en el campo tenían acceso a la escuela. Al volver a las aulas, a pesar de su avanzada edad, ellas luchan contra ese foco de exclusión social y de negación del derecho a la educación que todavía hoy se manifiesta en la región nordestina donde viven. ${ }^{47} \mathrm{La}$ invisibilidad de las personas mayores,

práctica profesional en el curso de Pedagogía del campo (Sousa, 2011; Souza y Molina, 2016) haciendo confluir las perspectivas de la sociolingüística y de los estudios de literacidad.

44 Paulo Freire usa el vocablo para llamar la atención sobre el carácter ideológico de la palabra "nortear" y así dar visibilidad a la perspectiva del hemisferio sur, contrariando la perspectiva euronorteamericana que niega racionalidad a los sistemas de conocimiento producidos fuera de ese eje, considerado de referencia universal (Adams, 2018).

45 Atribuido a Fábio Mandingo, miembro del grupo de investigación Poetas e escritores marginais de la Universidad Estatal de Bahia (UNEB).

46 Coordinadora de grupos de investigación sobre la literacidad con sede en la Universidad Estatal de Bahia: Grupo de Estudos e Pesquisas em História, Educação e Gênero; Grupo de Estudos em Resiliência, Educação e Linguagens; Grupo de Pesquisa Autobiografia Formação História Oral.

47 El Nordeste brasilero tiene la tasa más alta de población analfabeta en el país, conforme datos del Instituto Brasileño de Geografía y Estadística (IBGE). su ausencia total de los debates públicos son indicios claros de la naturaleza de las políticas públicas brasileñas hacia la población mayor. En ese contexto, el estudio de A. de S. Pereira ayuda a esas matronas campesinas a salir del silencio profundo en que se encontraban y que no es solo de ellas, "pues entraña el continente perdido de las vidas sumergidas en el olvido" (2014, p. 66). ${ }^{48} \mathrm{Al}$ hacerlo, nos muestra mujeres que deciden incursionar en el espacio de la escuela por sus potencialidades para embarcarse en nuevos y diversos rumbos que pueden seguir sus vidas, en principio, cuando, liberadas del trabajo por la propia vejez, sienten que pueden volverse hacia sí mismas. ${ }^{49}$

\section{La formación revisitada: prácticas de literacidad académica}

En la conclusión de su tesis sobre las prácticas escolares de literacidad en una clase de educación para jóvenes y adultos, Pedralli nos advierte que el ámbito académico, especialmente, cuando se trata de la universidad pública, debe poner cuidado a los resultados de su investigación, los cuales sugieren que las fuerzas de una tradición escolar excluyente continúan determinando acciones didácticas e interacciones que 'no suceden' en el aula (Matencio, 2001). Entiende Pedralli que "el 'acto docente' se gesta, en gran medida, en la formación inicial y se alimenta o resignifica en la formación continuada; o, tal vez sea más apropiado decir: no se está gestando en esas mismas formaciones" (Pedralli,

Ver más en: https://www.portalt5.com.br/noticias/ brasil/2017/12/34946-nordeste-apresenta-maior-taxade-analfabetismo-do-brasil-aponta-ibge

48 Original: "pois ele envolve o continente perdido das vidas submersas no esquecimento". Para Pedralli (2014), que distingue entre 'silenciarse' y 'callar', el silencio de esas mujeres se integra al conjunto de voces históricamente excluidas de la escuela.

49 Lo que no significa que encuentren en el nuevo espacio que ocupan modelos didáctico-pedagógicos diferentes de los que encuentran las mujeres que participaron de la investigación de Pedralli (2014), que, efectivamente, les niegan la posibilidad de resignificación de sus prácticas de literacidad (v. Kleiman, 2013). 
2014, p. 277)..$^{50}$ Además, se lamenta de que los hallazgos sobre la complejidad subyacente al acto docente no se hayan convertido en cambios ni en la formación académica ni en las políticas públicas relacionadas con la formación docente, ${ }^{51}$ puesto que en ese caso, tal vez sería otro el cuadro desalentador que encontró en los salones de clase analizados.

Es un hecho que, desde la promulgación de la Ley de Directrices y Bases de la Educación Nacional en 1996, en conjunto con la definición de metas del Plan Nacional de Educación (PNE), hubo un aumento sostenido hasta 2015, en la oferta a los profesores de cursos de formación inicial, formación en servicio y formación continuada. Pero debe señalarse que sin una mejora en la formación del profesor brasileño y sin una mayor inversión de fondos para implementar las políticas públicas destinadas a ese fin, no existe ninguna posibilidad de alcanzar las metas educacionales previstas, tan modestas en el plan internacional. En ese escenario, el tema de la formación docente, antes en manos de investigadores del área de educación, ha atraído cada vez más a estudiosos de diferentes áreas. La lingüística aplicada no es ajena a este interés y, en consecuencia, la formación del profesor ha sido objeto de intensa investigación por la vertiente sociocultural y sociohistórica de los estudios sobre literacidad, por diversas redes de investigación del país.

Este corpus es de una gran riqueza y complejidad (De Grande, 2007), en función de la naturaleza del fenómeno analizado, consistente en prácticas

50 En el original: "o 'agir docente' é gestado, em boa medi$\mathrm{da}$, na formação inicial e alimentado ou ressignificado na formação continuada; ou, talvez mais apropriadamente: não está sendo gestado nessas mesmas formaçôes..."

51 También llama la atención de los gestores de políticas públicas que, en general, ofrecen a los profesores de EJA condiciones de trabajo tan poco atractivas que ese segmento de actuación docente no pasa de ser mera complementación de ingresos, sin compromisos ni exigencias. discursivas, objetivación de saberes sobre la lengua y el lenguaje, construcción de categorías y representaciones, modos de actualizar los conocimientos profesionales. Todos esos elementos, articulados entre sí, acuden en la configuración de un corpus múltiple por su diversidad discursiva y por la complejidad de los hilos dialógicos que se tejen en las redes de formación, que incluyen desde artefactos como el cuaderno hasta el discurso del profesor formador y de los docentes en formación.

El análisis de la interacción permite entrever que las categorías usadas por alfabetizadores y profesores en formación inicial o continuada, que muchas veces parecen ajenas a la esfera académica (Santos, 2005), no representan una ruptura radical con los conceptos presentes en los textos del discurso científico o de divulgación científica utilizados en la formación, sino que, por el contrario, permiten identificar un proceso de reformulación de textos (retextualización) de esos géneros académicos que va haciendo las categorías más familiares; así, desde este marco, los profesores y alumnos de los cursos de pedagogía y de letras trabajarían, a partir de categorías locales, justamente para que no haya una ruptura en el diálogo entre el formador académico y el alfabetizador o profesor en formación. Examinar esas reformulaciones textuales produce también conocimientos sobre las prácticas de lectura y escritura académicas y sobre el proceso de inserción de los estudiantes en el campo profesional. $^{52}$

Además de la sintonía metodológica, algunos estudios adoptan una opción teórica en común, interaccionista y dialógica, que encuentra en el dialogismo del Círculo de Bakhtin, o en el interaccionismo sociodiscursivo de Bronckart, las fuentes conceptuales que les permiten examinar

52 El grupo Núcleo de Estudos em Linguagens, Letramentos e Formação (NELLF), con sede en la Universidad Católica (PUC) de Minas Gerais ha invertido fuertemente en esta línea de investigación, presente, por ejemplo, en los trabajos de Matencio (2002; 2003; 2005; 2006; 2007), Matencio y Silva (2003); Silva y Matencio (2005). 
los datos sobre los usos de la lengua sin perder de vista la plasticidad de los procesos implicados en las situaciones de interacción, en las acciones de producción de sentidos y en la construcción de representaciones. En menor cantidad, enfoques más preocupados con aspectos sociales y psicológicos de la formación encuentran sus fuentes teórico-metodológicas en las teorías de las representaciones sociales de la psicología social, con base en el fundamento de que la noción de representaciones sociales permite capturar los sentidos que los participantes de determinado grupo, o comunidad, al participar de algún proyecto o alguna práctica, le atribuyen colectivamente a un concepto al articularlo con otros conceptos y prácticas sociales interdependientes (Assis, 2016). ${ }^{53}$

En las implicaciones y conclusiones de estos trabajos existe también una semejanza notable, pues todos apuntan que la acción de enseñar es social, así como lo es la construcción de conocimientos, y que de ambos procesos emergen historias y subjetividades que se atraviesan y que no deben ser ignoradas por los formadores.

Tradicionalmente, los estudios sobre la formación del profesor han focalizado las acciones didácticopedagógicas en el salón de clases. En la década de los 90, por ejemplo, el análisis recaía sobre el discurso del profesor - en ese contexto de producción el silencio del alumno imperaba y no había interacciones que superasen la respuesta monosilábica del alumno-; en razón de eso, se constataba fácilmente la ausencia de prácticas escolares esperadas en una situación de enseñanza y aprendizaje. Un ejemplo de esa ausencia son las prácticas de explicación, examinadas por Signorini y Kleiman (1994). Las autoras relatan que no se encontró, en horas y horas de grabación, ninguna explicación, una operación del discurso letrado,

53 También el grupo de Minas Gerais, ya mencionado, ha sido uno de los más productivos del país en esa línea de investigación en el ámbito de la formación docente, evidenciado, por ejemplo, en los trabajos de Assis (2014); Assis y Lopes (2010); Silva, Assis y Barros (2013). que se construye dialógicamente por medio de un ajuste progresivo de perspectivas entre alumno y profesor, con la finalidad de categorizar, definir, anclar un determinado objeto del discurso en el mundo real. En ese tipo de investigación no había culpabilidades atribuidas al profesor por la falta de operaciones explicativas, pero tampoco el investigador académico asumía responsabilidad por la formación de ese profesional.

El interés en el efecto de acciones del profesor sobre el aprendizaje del alumno es más tardío, y ese nuevo foco ha transformado los estudios más recientes que focalizan los actos del profesor. ${ }^{54}$ En un estudio reciente, ya mencionado al iniciar esta sección, Pedralli (2014) examina la organización de las acciones didáctico-pedagógicas de un curso de EJA e interactúa con alumnas del curso para determinar si, en la interpretación de esas estudiantes - mujeres adultas trabajadorasobtenida en ruedas de conversación, a través de interacciones complementadas con preguntas, respuestas, comentarios, esas acciones exhiben algún potencial para la resignificación de las prácticas de literacidad de esas mujeres en sus procesos de apropiación de la lengua escrita. Los resultados, así como los de A. de S. Pereira (2014), revelan mucho sobre la pobreza de las prácticas letradas autónomas (Street, 1983), movilizadas en esos cursos, en dos regiones que van del nordeste al sur del país.

El interés por la contribución de los estudios de literacidad a la formación del profesor no es nuevo - es anterior incluso a la consolidación del paradigma de Street (1983)—; y dicho paradigma explica, por la oposición entre el modelo ideológico y el modelo autónomo de la literacidad, la ineficiencia de enseñar prácticas que no tienen aplicación en la vida social fuera del ámbito escolar. A modo

54 Como los trabajos del grupo Cultura Escrita e Escolarização, de la Universidad Federal de Santa Catarina (Pedralli, 2014; Cerutti-Rizzatti, Kindermann y Muza, 2016; Cerutti-Rizzatti, Mossmann e Irigoite, 2013; Souza, 2016). 
de ejemplo, los trabajos lexicográficos de Santos, discutidos en la sección anterior, son derivaciones de su interés inicial por la formación de las alfabetizadoras del sertón semiárido (C. B. Santos, 2005; Santos y Lima, 2013; Santos, 2016)..$^{55}$ Recordamos, también, que a finales de la década de 1990, un grupo de docentes de la Universidad Católica (PUC) de Minas Gerais, formadores de profesores de portugués, planearon e implementaron un conjunto de reformas del curso de letras, cuyos principios orientadores son presentados por Silva, Matencio y Assis (2001) en un texto donde especifican que la construcción de competencias docentes implica, entre otros aspectos, conocimientos sobre los usos y funciones del lenguaje, en textos orales y escritos y, por lo tanto, está asociada a la comprensión de la literacidad en lo que ese proceso tiende a decir sobre la inserción del estudiante en formación en el universo de la lengua escrita.

A pesar de los objetivos, objetos, metodologías y marcos teóricos semejantes, las investigaciones no corren el riesgo de homogenización debido al carácter situado de las prácticas examinadas: la premisa del proceso de formación es la construcción conjunta, colaborativa de subjetividades, objetos de conocimientos, eventos letrados, con base en la interacción. Descartada esa posibilidad de homogenización, lo que se obtiene es una rica y variada gama de situaciones y escenarios, irrepetibles, únicos y, en menor o mayor grado,

55 En esos trabajos el investigador analiza cómo las alfabetizadoras organizan los conocimientos relacionados con los objetos de enseñanza, en este caso categorías sobre el texto, con el objetivo de recuperar las vías usadas en la construcción y organización de los saberes teóricos por profesores que están muy distantes — tanto espacial como epistemológicamente-, de los centros de producción del saber, como es el caso del alfabetizador en formación en el sertón bahiano. Su grupo Políticas de Letramento para a Comunicação Intercultural (Práticas de Escritas nas Escolas e nas Universidades do Semiárido), con sede en la Universidad del Estado de Bahía, también examina cuestiones similares en el contexto de formación de profesores indígenas (v. Gomes y Santos, 2013; C. Santos, 2016). ilustrativos e informativos de los procesos de formación de lectores-escritores o docentes.

Gradualmente, con la finalidad de examinar su papel en la formación, la mirada del investigador comienza a dirigirse a los artefactos usados para dar sentidos a las prácticas letradas o en la escuela -el libro didáctico (Bunzen, 2009), los modelos de enseñanza (como los proyectos de literacidad analizados en la sección anterior) - o en la universidad - diarios de aprendizaje de los alumnos de Letras en formación inicial (Tapias-Oliveira, 2006); asesoría pedagógica en contexto editorial y formación en servicio (Vianna, 2017); Hora de Trabalho Pedagógico Coletivo ${ }^{56}$ (De Grande, 2015), orientaciones para el trabajo final de un curso de especialización para profesores experimentados (Pereira, 2017).

En su investigación, De Grande (2015) intenta identificar y analizar eventos de literacidad en las reuniones de profesoras/alfabetizadoras de los primeros años de la enseñanza básica. La noción de espacio del geógrafo brasileño Milton Santos fue usada por la investigadora para entender las fluctuaciones y recreaciones observadas en las prácticas de literacidad de las profesoras. Según las circunstancias físicas y las modalidades de participación en los espacios donde realizaban las reuniones - que eran todas de la esfera del trabajo-, se derivaba en diferencias que acarreaban distintas modulaciones de la interacción. Estas diferencias influenciaban la construcción de contextos de aprendizaje en los modos de participación de cada tipo de evento, en las relaciones entre las participantes, en las identidades y posicionamientos asumidos en la interacción, en los géneros movilizados y temas desarrollados.

La práctica docente supervisada (estágio supervisionado), ${ }^{57}$ tradicionalmente objeto de

56 Constructo de los órganos gubernamentales de São Paulo para denominar reuniones supuestamente formativas del cuerpo docente de cada escuela.

57 Que consideramos un artefacto, siguiendo la definición de Bartlett y Holland (2012). En la clasificación de Hamilton (2000), el artefacto parece ser siempre material. 
investigación en el área educacional, tímidamente va emergiendo como objeto de análisis de los estudios sobre literacidad de la lingüística aplicada, lanzando luz sobre algunos de los misterios (Lea y Street, 1998; Lillis y Scott, 2007) de las prácticas letradas en la esfera académica. $\mathrm{Al}$ analizar las prácticas letradas en las disciplinas relacionadas con la práctica profesional en su tesis doctoral, Valsechi (2016) nota la dificultad de considerarla como una práctica situada, puesto que los estudiantes en ese periodo de formación son insertados en esas prácticas de literacidad académica, ocultas, desvinculadas de su realidad y ajenas a sus propios propósitos de literacidad. Reichmann $(2015,2016)^{58}$ que, como Valsechi, inventa y explora la función de nuevos artefactos y eventos en sus cursos para estudiantes en periodo de práctica profesional, entiende dicha práctica como entre-lugar ${ }^{59}$ socioprofesional — que abarca la esfera académica y la esfera del trabajo- donde el practicante, al participar de los eventos híbridos en esas esferas, va construyendo

Para Pedralli (2014), que se apoya en Hamilton, los artefactos materiales permiten delimitar el constructo evento de literacidad: si la misma herramienta material hace parte de la interacción, se trata del mismo evento, si muda el artefacto, se configura otro evento.

58 Entre otras investigaciones del grupo al que pertenece Reichmann, Estudos em Letramentos, Interação e Trabalho (GELIT), con sede en la Universidad Federal de Paraíba (UFPB), podemos citar las tesis doctorales sobre prácticas profesionales de Farías (2017) y de Sant'ana (2016). Ver también Reichmann y Guedes Pinto (2018); Guedes Pinto (2010) y las publicaciones del Grupo ALLE/ AULA - Alfabetização, Leitura e Escrita/Trabalho Docente na Formação Inicial, con sede en la Universidad Estatal de Campinas (UniCAMP).

59 La proposición conceptual de Bhabha (1998, p. 20) caracteriza los espacios entre-lugar como "proveedores del terreno para la elaboración de estrategias de subjetivación - singular o colectiva - que dan inicio a nuevos signos de identidad y sitios innovadores de colaboración y contestación, en el acto de definir la propia idea de la sociedad”. En el original: “These 'in-between' spaces provide the terrain for elaborating strategies of selfhood - singular or communal- that initiate new signs of identity, and innovative sites of collaboration, and contestation, in the act of defining the idea of society itself. su identidad docente, con base en el redimensionamiento de lo observado en la escuela y en el propio proceso de formación.

El objeto de estudio de S. L. M. Pereira (2017) fue un programa de desarrollo educacional del estado de Paraná, considerado modelo desde su creación, diez años antes. Según la autora del trabajo, la interacción entre el docente académico y los profesores en formación sugiere que la formadora universitaria presupondría que el desarrollo de las prácticas de literacidad de la esfera del trabajo sería consecuencia del desarrollo de prácticas de literacidad de la esfera académica; esto explicaría el gran esfuerzo de la formadora universitaria para familiarizar a las profesoras en formación del programa orientado por ella con las prácticas de su esfera de actuación. De esta forma, se favoreció la afiliación de las profesoras a la teoría científica objeto de las orientaciones, así como se facilitó su apropiación de conocimientos y prácticas discursivas académicas. Sin embargo, en lo que atañe a las prácticas de literacidad de la esfera del trabajo, hubo pocos avances en la construcción de prácticas para la acción didáctico-pedagógica, con excepción de aquellos casos en que las propias profesoras en formación construían parámetros para la organización de tales acciones, basadas en sus usos de la lengua escrita en proceso de formación. Esto resulta, no obstante, en la atribución de funciones distintas y conflictivas a la escritura en los eventos de formación.

El análisis crítico de S. L. M. Pereira (2017) sitúa su estudio en el campo de la literacidad académica, ${ }^{60}$ cuyos trabajos se posicionan de modo contrario a los postulados y análisis elitistas que, en respuesta al bajo rendimiento de los estudiantes con nuevos perfiles que entraban a la universidad debido a la expansión de la enseñanza superior, atribuyen a esos recién llegados la responsabilidad por

60 En Brasil, letramento acadêmico. Los estudios sobre Letramento do Professor, del grupo con el mismo nombre, han sido caracterizados como un tipo de literacidad académico (v. Cristovão y Vieira, 2016). 
el declive de la calidad de la enseñanza en la universidad y por el fracaso del alumno. Pensamos como Sito (2016, p. 77) que, al transformar la institución que tradicionalmente fue agente de la investigación en un objeto de la investigación, esos estudios se han convertido en un elemento perturbador del statu quo universitario. Y eso, a pesar del poco efecto sentido hasta ahora, solo puede considerarse una manifestación de progreso.

Las investigaciones sobre literacidad académica surgidas en Inglaterra como línea específica de los estudios sobre literacidad (Lea y Street, 1998; Lillis y Scott, 2007) abrieron camino para conocer los modos de conocimiento y de apropiación del saber de grupos de gran vulnerabilidad social. No es necesario tomar ese camino, puesto que el poder y la autoridad están imbricados las prácticas de literacidad de la esfera académica, pero es importante aprovechar la oportunidad, o corremos el riesgo de que las asimetrías en la producción del conocimiento entre los ingresantes secularmente vedados en las puertas de la universidad no serán superadas en instituciones que usan la ideología del déficit para atribuir el fracaso al alumno, en vez de perspectivas inter- y multi-culturales para explicar la propia incompetencia.

La ya mencionada investigación de Sito (2016) nos muestra que, a pesar de un comienzo traumático, aun hostil, los alumnos ingresantes por políticas de acción afirmativa pueden construir por sí mismos narrativas exitosas con base en la creación de estrategias de uso del lenguaje para subvertir la colonialidad del saber, por medio de la creación de escrituras afirmativas. Al participar de ese proceso, ${ }^{61}$ redefiniendo su valoración de conocimientos, hasta hoy determinados por una matriz de poder colonial, la universidad puede evitar la

61 Ver, al respecto, el trabajo realizado por Martins (2017); Martins y Carvalho (2017) sobre educación indígena y sobre alumnos indígenas en la universidad. Martins es integrante del grupo Letramento do Profesor y coordina el grupo Linguagens em Tradução (LEETRA), con sede en la Universidad Federal de São Carlos (UFScar). reproducción de preconceptos que no son saludables ni para las poblaciones vulnerables, ni para la educación, ni para la universidad y mucho menos para el bienestar general de país.

\section{Una palabra final}

Muchos son los caminos que han emprendido los investigadores de las prácticas de literacidad en Brasil. El país es enorme, como dijimos al inicio, pero también son grandes las redes de investigadores del área que hemos presentado, la lingüística aplicada. Esta área se viene ocupando de los impactos de la lengua escrita en poblaciones cuyos modos de construir y organizar saberes huyen de "la norma" y se preocupan con este, tal como lo exigen estructuras elitistas y arcaicas que todavía determinan lo que cuenta y vale como saber.

Desde los primeros trabajos de investigación sobre las prácticas socioculturales e históricas de uso de la escritura, orientados al examen de la interacción entre sujetos no alfabetizados y sus alfabetizadoras, o entre sujetos con poca escolaridad y sus entrevistadores, los enfoques etnográficos privilegiados nos permitían vislumbrar las relaciones entre poder, clase social, concepciones sobre la lengua, tanto escrita como oral y sus consecuencias sobre los sujetos más vulnerables del punto de vista social. Los mitos, preconceptos y representaciones estigmatizadas que eran reproducidos en situaciones de comunicación intercultural, tan evidentes e incontestables, creíamos nosotros, nos iludían en cuanto a su fuerza para mudar el rumbo de la formación del profesor y, consecuentemente, la enseñanza de la lectura y la escritura en la escuela. Pero hubo impactos. Los modos de aproximación al objeto de estudio, la lengua escrita, a través de análisis lingüístico, enunciativo y discursivo en las interacciones se ha constituido en una marca distintiva de la investigación sobre la literacidad realizada bajo la égida de la lingüística aplicada, con finalidades aplicadas, primero en el contexto de alfabetización de adultos y en seguida en el de la formación del profesor. 
Una característica de las tendencias investigativas discutidas en este trabajo, reiterada en diversos momentos del artículo, es su potencialidad para desvelar y hacer emerger voces y posicionamientos que no son generalmente escuchados, vistos, sentidos en la escuela o la universidad, a pesar de que revelan la formación social de los alumnos, sus valores y opiniones y sugieren formas innovadoras de recortar la realidad y de formar representaciones sobre los objetos de enseñanza y aprendizaje. Diversos estudios sobre alumnos pobres, negros e indígenas admitidos en la universidad por la primera vez en la historia sugieren caminos para repensar estrategias y actividades de formación que superen las contradicciones históricas de una universidad que, a pesar de ocupar un lugar de promotora de formación para el trabajo, de divulgadora del pensamiento científico, en fin, de agencia de literacidad, ignora los modos de conocer de su alumno.

Muchos son los trabajos a lo largo y ancho del país que, valorizando aspectos socioculturales, conocimientos locales, artefactos culturales disponibles en el proceso de construcción de saberes, y aceptando el compromiso social con los grupos más vulnerables de nuestra sociedad, nos permiten inferir cuales son las transformaciones por las cuales la investigación y docencia académicas deben pasar para que sujetos en contextos considerados periféricos (por su relación con las instituciones donde circulan prácticas de literacidad consideradas legítimas por los grupos de poder) asuman las riendas de su continuo proceso de literacidad. Si actuamos con base en esas inferencias, mudando currículos y disciplinas de los cursos de pedagogía y letras, abandonando propuestas académicas irrelevantes en la arena de la lucha cultural y epistemológica, podremos, quizás, comenzar a pensar en formar profesionales de la educación empoderados que, acogiendo las voces de alumnos y alumnas, podrán entonces contribuir con los cambios educacionales que se hacen tan necesarios a la sociedad.

Para ese lector con quien los investigadores aquí representados más quieren dialogar, los profesores, me atrevo a expresar un compromiso latente en todas las investigaciones: el de no olvidar que ocupamos un mismo espacio, así como también compartimos un mismo tiempo con las poblaciones marginalizadas, y como ya dije en otros trabajos, tenemos nuestras historias entrelazadas porque tenemos necesidades y expectativas comunes.

\section{Referencias}

Adams, T. (2008). Verbete Sulear. En D. Streck, E. Rediny y J. J. Zitkoski (Eds.), Dicionário Paulo Freire (pp. 96398). Belo Horizonte: Autêntica.

Assis, J. A. (2014). Representações sobre os textos acadêmico-científicos: pistas para a didática da escrita na universidade. Estudos Linguísticos, 43, 801-815.

Asiss, J. A._(2016). Representações sociais e letramento. En A. B. Kleiman y J. A. Assis (Orgs.), Significados e ressignificaçôes do letramento: desdobramentos de uma perspectiva sociocultural sobre a escrita (pp. 63-88). Campinas: Mercado de Letras.

Asiss, J. A._y Lopes, M. A. P. T. (2010). Ethos, discursos e representações na atividade de avaliação de textos escritos: pistas de um processo de formação de professores. Scripta, 13, 71-94.

Bhabha, H. K. (1998). O local da cultura. Belo Horizonte: Editora UFMG.

Bakhtin, M. M. (1990). Estética de la creación verbal (4a ed.). México: Siglo XXI.

Bartlett, L. (2007). To seem and to feel: Situated identities and literacy practices. Teachers College Record, 109(1), 51-69.

Bartlett, L. y Holland, D. (2002). Theorizing the space of literacy practices. Ways of Knowing Journal, 2(1), 10-22. Recuperadodehttps://www.academia.edu/938265/ Theorizing the Space of Literacy Practices

Barton, D. y Hamilton, M. (1998). Local literacies: Reading and writing in one community. Nueva York: Routledge.

Batista, A. A. G. (1998). Os professores são "não-leitores"? En M. Marinhoy y C. S. R. Silva (Eds.), Leituras do professor (pp. 23-60). Campinas: Mercado de Letras/ Associação de Leitura do Brasil.

Borges da Silva, S. B. (2001). PCN e a formação do professor: quais as contribuições possíveis? En A. Kleiman (Org.), Formação do professor: Perspectivas da linguistica aplica$d a$ (pp. 95-114). Campinas: Mercado de Letras.

Borges da Silva, S. B. (2003). Formação de professores e PCN: Um olhar sobre a leitura e o material de leitura. Tesis 
de doctorado, Universidade Estadual de Campinas (Unicamp), Campinas, sp, Brasil.

Borges da Silva, S. B._(2005). Leituras de professoras. En A. B. Kleiman y M. L. Matencio (Eds.), Letramento e formação do professor: práticas discursivas, representaçôes e construção do saber (pp. 143-164). Campinas: Mercado de Letras.

Borges da Silva, S. B. (2006). A retextualização dos conceitos de letramento, texto, discurso e gêneros do discurso nos PCN de língua portuguesa. Trabalhos em Linguistica Aplicada, 45, 225-238.

Borges da Silva, S. B. (2016). Etnografia e autoetnografia na formação de professores. En A. B. Kleiman y J. A. Assis (Eds.), Significados e ressignificações do letramento (pp. 120-135). Campinas: Mercado de Letras.

Bourdieu, P. (1993 [1983]). Language and symbolic power. Cambridge: Polity Press.

Brandt, D. y Clinton, K. (2002). Limits of the local: Expanding perspectives on literacy as a social practice, Journal of Literacy Research, 34(3), 337-356.

Brasil. (1997). Parâmetros curriculares nacionais: primeiro e segundo ciclos do ensino fundamental. Lingua portu-

Brasil. (1998a). Parâmetros curriculares nacionais: terceiro e quarto ciclos do ensino fundamental. Lingua portuguesa. Brasilia: Secretaria de Educação Fundamental.

Brasil (1998b). Referencial curricular nacional para a educação infantil. Brasilia: MEC. Disponible en http://portal. mec.gov.br/seb/arquivos/pdf/rcnei_voll.pdf

Brasil (1998c). Diretrizes nacionais para o ensino médio. Brasilia: MEC.

Brasil (1998d). Referencial curricular nacional para as escolas indigenas. Disponible en https://www.ufmg.br/copeve/Arquivos/2018/fiei_programa ufmg2019.pdf

Brasil (1999a). Referenciais para formação de professores. Brasilia: MEC.

Brasil (1999b). Alfabetização. Parâmetros em ação. Brasilia: MEC. Disponible en http://portal.mec.gov.br/seb/ arquivos/pdf/pen_acao/pcnacao alf.pdf

Brasil (2000). Alfabetização. Parâmetros em ação. Brasilia: MEC.Brasil (2002a). Referenciais para a formação de professores indigenas. Brasilia: MEC. Disponible en http://portal.mec.gov.br/seb/arquivos/pdf/Livro.pdf

Brasil (2002b). Proposta curricular para a educação de jóvens e adultos. Brasilia: MEC. Disponible en http://portal. mec.gov.br/secad/arquivos/pdf/eja livro 01.pdf
Brasil. (2017). Base nacional comum curricular. Brasilia: MEC.

Britto, L. P. L. (1998). Leitor interditado. En M. Marinhoy y C. S. R. Silva (Eds.), Leituras do professor (pp. 6178). Campinas: Mercado de Letras/ Associação de Leitura do Brasil.

Bunzen, C. dos. S (2009). Dinâmicas discursivas na aula de português: usos do livro didático e projetos didáticos autorais. Tese de doutorado, Universidade Estadual de Campinas (Unicamp), Campinas, sp, Brasil.

Certeau, M. (1994). A invenção do cotidiano: artes de fazer. Petrópolis, RJ: Vozes.

Cerutti-Rizzatti, M. E., Mossmann, S. E. e Irigoite, J. C. (2013). Estudos em cultura escrita e escolarização: uma proposição de simpósio entre ideários teóricos de base histórico-cultural na busca de caminhos metodológicos para pesquisas em linguística aplicada. Fórum Linguístico, 10(1), 48-58.

Cerutti-Rizzatti, M. E., Kindermann, C. A. y Muza, M. L. N. (2016). (Re)pensando a formação continuada para os componentes curriculares de linguas. Desafios metodológicos para a formação continuada dos/das profissionais da educação (pp. 51-74). Florianópolis: Secretaria Municipal de Educação de Florianópolis.

Cope B. y Kalantzis, M. (2000) (Eds.). Multiliteracies: literacy learning and the design of social futures. Londres: Routledge.

Correa, J. A. M. (2010). A professora leitora na Amazônia: narrativas, identidades e travessias. Tese de doutorado, Universidade Estadual de Campinas (Unicamp), Campinas, J. A., Brasil.

Cristovão, V. L. L. y Vieira, I. R. (2016). Letramentos em língua portuguesa e inglesa na educação superior brasileira: marcos e perspectivas. Ilha do Desterro, 69(3), 209-221.

Cunha, R. C. (2010a). Jornal escolar: raio de ações, rede de significaçôes. Reconfiguração do ensino de língua materna e dinamização da formação continuada do professor. Tese de doutorado, Universidade Estadual de Campinas (Unicamp), Campinas, sp, Brasil.

Cunha, R. C. (2010b). O jornal escolar sob a ótica do ensino de gênero e da formação continuada do professor. En C. Vóvio, L. Sito, y P. de Grande, P. (Eds.), Letramentos: rupturas, deslocamentos, e repercussöes de pesquisas em linguistica aplicada (pp. 141-161). Campinas, SP: Mercado de Letras.

Cunha, R. C.; Kleiman, A. B. y Tinoco, G. (2013). Projetos de letramento no ensino medio. En C. Bunzen y M. 
Mendonca, (Eds.), Múltiplas linguagens para o ensino médio (pp. 69-83). São Paulo: Parábola Editorial.

Silva, L. F. da (2012). Formação de professoras: aprendendo e ensinando a ler e escrever. Dissertação de mestrado, Universidade Federal da Bahia (UfBA), Salvador, BA, Brasil.

De Grande, P. B. (2007). Desafios da pesquisa qualitativa: um percurso metodológico inicial. Lingua, Literatura e Ensino, 2, 101-109 (UNICAMP).

De Grande, P. B. (2015). Formação continuada no local de trabalho do professor: possibilidades de agência e construção de sentidos para a docência. Tese de doutorado, Universidade Estadual de Campinas (UNICAMP), Campinas, sp, Brasil.

Descardesi, M. A. (1992). O concurso público: um evento de letramento em exame. Dissertação de mestrado, Universidade Estadual de Campinas (UNICAMP), Campinas, sP, Brasil.

Erickson, F. y Shultz, J. (1981). When is a context? Some issues and methods in the analysis of social competence. En J. L. Greeny y C. Wallat (Eds.), Ethnography and language in educational settings. (vol. v, pp. 147 150). Norwood, NJ: Ablex Publishing House.

Farias, L. F. P. (2017). O estágio supervisionado no curso de letras: uma trama enredada pelas práticas de letramento e representaçôes do trabalho docente. Tese de doutorado, Universidade Federal da Paraíba (UfPB), João Pessoa, PB, Brasil.

Frascolla, A. (2017). Fotonovela digital: um projeto de letramento. Dissertação de mestrado, Universidade Federal da Bahia, Salvador, BA, Brasil.

Freire, A. M. (1989). Analfabetismo no Brasil. Da ideologia da interdição do corpo à ideologia nacionalista, ou como deixar sem ler e escrever desde as Catarinas (Paraguaçu), Filipas, Madalenas, Anas, Genebras, Apolônias e Grácias até os Severinos. São Paulo: Cortez.

Freire, P. (1970). A pedagogia do oprimido. Petrópolis, RJ: Vozes.

Freire, P. (1980). Educação como prática da liberdade (10ª ed.). Rio de Janeiro: Paz e Terra.

Freitas, M. T. U. (2018). Letramentos queer na formação de professorxs de linguas: complicando e subvertendo identidades no fazer docente. Tese de doutorado, Universidade Federal de Goiás (UFGO), Goiânia, Go, Brasil.

Gee, J. P. (1986). Orality and literacy: From the savage mind to ways with words. TESOL, 20(4), 719-746. doi: $10.2307 / 3586522$
Goffman, E. (1963). Stigma. Notes on the management of spoiled identity. Nueva York: Simon y Schuster.

Gomes, K. y Santos, C. B. dos (2013). Cultura, letramento e comunidade indígena. Grau Zero: Revista de Crítica Cultural, 1, 86-95.

Gomes, K. y Santos, C. B. dos (2016). A identidade enunciativa na escrita de professoras indigenas. En A. B. Kleimany y J. A. Assis, (Eds.), Significados e ressignificaçôes do letramento (pp. 199-122). Campinas, SP: Mercado de Letras.

Goody, J. (1977). The domestication of the savage mind. Cambridge: Cambridge University Press.

Goody, J. y Watt, I. (1972). The consequences of literacy. En P. P. Giglioli (Ed.), Language and social context (pp. 311-353). Londres: Penguin.

González, A. (2001). Killer books: Writing, violence, and ethics in modern Spanish American narrative. Austin: The University of Texas Press.

Graff, H. J. (1995 [1979]). Os labirintos da alfabetização. Reflexões sobre o passado e o presente da alfabetização. The literacy myth: Literacy and social structure in the $19^{\text {th }}$ century. Porto Alegre: Artes Médicas.

Guedes Pinto, A. L. (2002). Rememorando trajetórias da professora-alfabetizadora: a leitura como prática constitutiva de sua identidade e formação profissionais. Campinas, sp: Mercado de Letras.

Guedes Pinto, A. L. (2005). Fragmentos de historias de lectura y escritura de profesoras-alfabetizadoras en la ciudad de Campinas, São Paulo, Brasil, en la contemporaneidad del siglo xx. En M. V. González de la Peña (Ed.), Mujer y cultura escrita-del mito al siglo XXI (pp. 251-266). Gijón: Trea.

Guedes-Pinto, A. L. (2012). Práticas de escrita no ensino universitário e suas relações com a formação docente. Scripta, 16, 137-149.

Guedes-Pinto, A. L. (2016). Les dires par écrit des étudiants stagiaires: la qualité d'auteur et la formation des enseignants dans le rapport de stage. Mélanges CRAPEL, $37,143-153$

Hall, S. (1998). A identidade cultural na pós-modernidade. [Traduzido ao português de The question of cultural identity]. $2^{\mathrm{a}}$ ed. Rio de Janeiro: DPYA.

Heath, S. B. (1983). Ways with words. Language, life and work in communities and classrooms. Cambridge: Cambridge University Press.

Kersch, D. F. y Guimarães, A. M. M. (2012). A construção de projetos didáticos de leitura e escrita como re- 
sultado de uma proposta de formação continuada cooperativa. Revista Brasileira de Linguística Aplicada, 12, 533-556.

Kleiman, A. B. (1991). Letramento e escolarização. Uma pesquisa para uma prática abrangente. (Relatório de Pesquisa). Brasília: CNPq.

Kleiman, A. B. (Ed.). (1995). Os significados do letramento: uma nova perspectiva sobre a prática social da escrita. Campinas: Mercado de Letras.

Kleiman, A. B. (1998). A construção de identidades em sala de aula. Um enfoque interacional. En I. Signorini (Ed.), Lingua (gem) e identidade (pp. 267-302). Campinas, sp: Mercado de Letras.

Kleiman, A. B. (2000). O processo de aculturação pela escrita: ensino da forma ou aprendizagem da função? In Kleiman, A. B. y Signorini, I. (Eds.), O ensino e a formação do professor: alfabetização de jovens e adultos (pp. 223-243). Porto Alegre: Artmed.

Kleiman, A. B. (2006). Processos identitários na formação profissional: o professor como agente de letramento, En M. Corrêa y F. Boch (Eds.), Ensino de língua: letramento e representações (pp. 75-91). campinas: mercado de letras.

414 Kleiman, A. B. (2013). Agenda de pesquisa e ação em linguística aplicada: problematizações. En L. P. Moita Lopes (Org.), Linguistica aplicada na modernidade recente: Festschrift para Antonieta Celani (pp. 39 58). São Paulo: Parábola.

Kleiman, A. B. y Assis, J. A. (Org.). (2016). Significados e ressignificaçôes do letramento. Desdobramentos de uma perspectiva sociocultural sobre a escrita. Campinas, SP: Mercado de Letras.

Kuhnheim, J. S. (2014). Beyond the page. Poetry and performance in Spanish America. Tucson, AR: The University of Arizona Press.

Lahire, B. (2001). O homem plural: as molas da acção. Lisboa: Instituto Piaget.

Lea, M. R. y Street, B. (1998). Student writing in higher education: an academic literacies approach. Studies in Higher Education, 23(2), 157-173.

Lillis, T. y Scott, M. (2007). Defining academic literacies research: issues of epistemology, ideology and strategy. Journal of Applied Linguistics, 4(1), 5-32. doi: 10.1558/japl.v4i1.5

Luria, A. R. (1976). Cognitive development. Its cultural and social foundations. Cambridge, Mass.: Harvard University Press.

Marques, I. B. S. (2016). A formação de professores de língua portuguesa: projetos de letramento, agência e empoderamento. En A. B. Kleiman, y J. A. Assis (Eds.), Significados e ressignificaçôes do letramento. Desdobramentos de uma perspectiva sociocultural da escrita (pp. 111-142). Campinas: Mercado de Letras.

Martins, M. S. C. (2017). Letramento acadêmico e oralidade: repensando termos à luz da presença indígena nas universidades brasileiras. Revista Scripta, 21, 127-147.

Martins, M. S. C. y Carvalho, G. R. G. (2017). Escrita acadêmica e identidade à luz da presença indígena na Universidade Federal de São Carlos. São Carlos: EDUFSCar.

Matencio, M. L. M. (1999). Estudo da lingua falada e aula de lingua materna: uma abordagem processual da interação professor/alunos. Tese de Doutorado, Universidade Estadual de Campinas (Unicamp), Campinas, sp, Brasil.

Matencio, M. L. M. (2001). Estudo da lingua falada e aula de lingua materna: uma abordagem processual da interação professor/alunos. Campinas, SP: Mercado das Letras.

Matencio. M. L. M. (2002). Atividades de (re)textualização em práticas acadêmicas : um estudo do resumo. Revista Scripta, 6(11), 109-122.

Matencio. M. L. M. (2006). Letramento na formação do professor - integração a práticas discursivas acadêmicas e construção da identidade profissional. En M. L. G. Corrêa y F. Boch (Eds.), Ensino de lingua: representação e letramento (pp. 93-106). Campinas, SP: Mercado de Letras.

Matencio. M. L. M. (2007). Gêneros discursivos na formação de professores: reflexões sobre a construção de saberes e o processo de letramento. En G. Gil, G. y M. H. V. Abrahão (Eds.), A formação do professor de linguas: os desafios do formador (pp. 189-199). Campinas: Pontes Editores.

Matencio, M. L. M. (2009). Estudos do letramento e formação de professores: retomadas, deslocamentos e impactos. Caleidoscópio, 7(1), 5-10.

Menezes, E. T. y Santos, T. H. (2001). Verbete Mobral (Movimento Brasileiro de Alfabetização). Dicionário Interativo da Educação Brasileira - Educabrasil. São Paulo: Midiamix. Retrieved from http://www. educabrasil.com.br/mobral-movimento-brasi leiro-de-alfabetizacao/

Moita Lopes, L. P. (org.). (2013). Linguística aplicada na modernidade recente: Festschrift para Antonieta Celani. São Paulo: Parábola.

Oliveira, C. (1994). O alfabetizador e a leitura: análise de uma experiência de formação em serviço. Dissertação 
de mestrado Universidade Estadual de Campinas (Unicamp), Campinas, sp, Brasil.

Oliveira, M. S. (2008). Projetos: uma prática de letramentos no cotidiano do professor de língua materna. En M. S. Oliveira y A. B.Kleiman (Eds.), Letramentos múltiplos: agentes, práticas, representaçôes (pp. 93-118). Natal, RN: EDUFRN.

Oliveira, M. S. y Santos, I. B. A. (2012). Políticas públicas na educação de jovens e adultos: projetos de letramento, participação e mudança social. EJA em Debate, I(1), 39-56. Instituto Federal de Santa Catarina.

Oliveira, M. S., Tinoco, G. M. A. M. y Santos, I. B. A. (2011). Projetos de letramento e formação de professores. Natal: Editora da UFRN-EDUFRN.

Pedralli, R. (2014). Na tessitura de encontros via escrita: vivências de mulheres em espaço escolar na EJA. Tese de doutorado, Universidade Federal de Santa Catarina (UFSC), Florianópolis, SC, Brasil.

Perus, F. (2005). ¿Qué nos dice hoy la ciudad letrada de Ángel Rama? Revista Iberoamericana, LXXI(211), [abril-junio], 363-372. Retrieved from: https://revista-iberoamericana.pitt.edu/ojs/index.php/.../5589

Pereira, A. da S. (2009). Memórias de letramento de idosos: a leitura e a escrita como bens simbólicos de inclusão e/ou de exclusão. Interdisciplinar: Revista de Estudos em Lingua e Literatura, 9. Recuperado de

Pereira, A. da S. (2013). Narrativas de vida de idosos: memórias, tradição oral e letramento. Salvador: EDUNEB.

Pereira, A. da S. (2014). Tempo de plantar, tempo de colher: mulheres idosas, saberes de si e aprendizagens de letramento em Saquinho. Tese de doutorado, Universidade do Estado da Bahia (UEBA), Salvador, BA, Brasil.

Pereira, I. (1997). A oralidade letrada de lideranças não-escolarizadas. Tese de doutorado, Universidade Estadual de Campinas (Unicamp), Campinas, sp, Brasil.

Pereira, S. L. M (2017). Usos da escrita na formação docente universitária e o letramento profissional do professor. Tese de doutorado, Universidade Estadual de Campinas (UNICAMP), Campinas, SP, Brasil.

Ratto, I. P. (1995). Ação política: fator de constituição do letramento do analfabeto adulto. En A. B. Kleiman (Ed.), Os significados do letramento: uma nova perspectiva sobre a prática social (pp. 267-290). Campinas, SP: Mercado de Letras.

Rama, A. (1985). A cidade das letras. [traduzido ao português de La Ciudad Letrada]. São Paulo: Brasiliense.

Reichmann, C. L. (2015). Letras e letramentos: escrita situada, identidade e trabalho docente no estágio supervisionado. Campinas: Mercado de Letras.
Reichmann, C. L. (2016). O estágio supervisionado como prática de letramento acadêmico-profissional. En A. B. Kleiman, A. B. y J. A. Assis (Eds.), Significados e ressignificaçôes do letramento (pp. 367-389). Campinas: Mercado de Letras.

Reichmann, C. L. y Guedes Pinto, A. L. (2018). Horizontes (im)possiveis no estágio: práticas de letramento e formação de professores de linguas. Campinas: Pontes Editores.

Ribeiro, D. (1995). O povo brasileiro. A formação e o sentido do Brasil. São Paulo: Companhia das Letras.

Rojo, R. H. R. (2012). Pedagogia dos multiletramentos: diversidade cultural e de linguagens na escola. En R. H. R. Rojo y E. Moura (Eds.), Multiletramentos na escola (pp. 11-31). São Paulo: Parábola.

Sant'ana, T. (2016). A (re)construção da identidade docente no percurso estagiária - professora iniciante em língua portuguesa. Tese de doutorado, Universidade Federal da Paraíba (UfPB), João Pessoa, PB, Brasil.

Santos, C. B. dos (2005). 'Um assunto puxa o outro': a representação da coerência textual na formação do alfabetizador. Tese de doutorado, Universidade Estadual de Campinas (Unicamp), Campinas, sp, Brasil.

Santos, C. B. dos. (2016). Lexicografia, culturas do semiárido e formação de educadores. En C. B. dos Santos y R. de C. R. de Queiroz (Eds.), As palavras e as culturas. Estudos da relação entre léxico e cultura na realidade baiana (pp. 110-127). Salvador: EdunEB.

Santos, C. B. dos y Lima, M. N. M. (2013). A prática lexicográfica na formação do professor indígena. Pontos de Interrogação: Revista de Critica Cultural, 2, 67-78.

Santos, I. B. A. (2012). Projetos de letramento na educação de jovens e adultos: o ensino da escrita em uma perspectiva emancipatória. Tese de doutorado, Universidade Federal do Rio Grande do Norte (UfRN), Natal, RN, Brasil.

Signorini, I. y Kleiman, A. B. (1994). When explaining is saying: Teacher talk in adult literacy classes. En A. Álvarez y P. del Río (Eds.), Explorations in sociocultural studies. Education as cultural construction, 4 (pp. 217-226). España: Fundación Infancia y Aprendizaje.

Silva, J. Q. G., Matencio, M. L. M. y Assis, J. A. (2001). Formação inicial e o letramento do professor de português: uma proposta em implantação. En A. B. Kleiman (Ed.), A formação do professor. Perspectivas da linguistica aplicada (pp. 281-312). Campinas: Mercado de Letras.

Silva, J. Q. G. y Matencio, M. L. (2005). Referência pessoal e jogo interlocutivo: efeitos identitários. En A. B. 
Kleiman y M. L. M. Matencio (Eds.), Letramento e formação do professor: práticas discursivas, representaçôes e construção do saber (pp. 245-266). Campinas: Mercado de Letras.

Sito, L. R. S. (2010). "Ali está a palavra deles". Um estudo sobre práticas de letramento em uma comunidade quilombola do litoral do Rio Grande do Sul. Dissertação de mestrado, Universidade Estadual de Campinas (UNICAMP), Campinas, sp, Brasil.

Sito, L. R. S. (2016). Escritas afirmativas: estratégias criativas para subverter a colonialidade em trajetórias de letramento acadêmico. Tese de doutorado, Universidade Estadual de Campinas (UNICAMP), Campinas, sP, Brasil.

Scribner, S. y Cole, M. (1981). The psychology of literacy. Cambridge: University Press.

Soares, M. (1998). Letramento: um tema em três gêneros. Belo Horizonte: Autêntica.

Souza, A. L. S. (2009). Letramentos de reexistência: culturas e identidades no movimento Hip Hop. Tese de doutorado, Universidade Estadual de Campinas (UNICAMP). Campinas, sp, Brasil.

Souza, A. L. S. (2011). Letramentos de reexistência: poesia, grafite, música, dança: hip hop. São Paulo: Parábola.

Sousa, P. de (2016). Cultura escrita e escolarização: participação em e ampliação dos usos sociais da escrita por sujeitos oriundos de um programa de correção de fluxo. Dissertação de mestrado, Universidade Federal de Santa Catarina, Florianópolis, sc, Brasil.

Sousa, R. M. (2011). Práticas de letramento: produção textual coletiva na formação do docente do campo. En M. C. Molina y L. M. Sá (Eds.), Licenciaturas em educação do campo: registros e reflexóes a partir das experiências-piloto (UFMG;UnB;UFBA e UFS) (pp. 275-288). Belo Horizonte: Autêntica.

Sousa, R. M., Molina, M. C. y Araujo, A. C. (Eds.). (2016). Letramentos múltiplos e interdisciplinaridade na licenciatura em educação do campo. Brasilia: UnB.

Street, B. V. (1984). Literacy in theory and practice. Cambridge: Cambridge University Press.

Street, B. V. (1995). Social literacies: critical approaches to literacy in development, ethnography and education. Londres: Longman.
Tapias-Oliveira, E. (2006). Construção identitária profissional no Ensino Superior: prática diarista e formação do professor. Tese de Doutorado, Universidade Estadual de Campinas (UniCAMP), Campinas, sp, Brasil.

Tfouni, L. V. (1988). Adultos não alfabetizados. O avesso do avesso. Campinas: Pontes Editores.

Tinoco, G. M. A. (2008). Projetos de letramento: ação e formação de professores de língua materna. Tese de doutorado, Universidade Estadual de Campinas (UNICAMP), Campinas, sP, Brasil.

Tinoco, G. M. A. M. (2011). Práticas sociais, leitura-escrita, ensino-aprendizagem: elementos constituintes dos projetos de letramento. En S. M. Serrani (Ed.), Letramento, discurso e trabalho docente (pp. 197-210). Vinhedo, sp: Horizonte.

Valsechi, M. C. (2016). Afinal, o que é o estágio supervisionado? De labirinto a entrelugar: o estágio proposto pela universidade na visão dos estagiários. Tese de doutorado, Universidade Estadual de Campinas (UNICAMP), Campinas, sp, Brasil.

Vianna, C. A. (2017). Uma experiência de assessoria pedagógica em contex to editorial: letramento do professor para o local de trabalho. Tese de doutorado, Universidade Estadual de Campinas (UnICAMP), Campinas, sp, Brasil.

Vianna, C. A.; Sito, L. S.; Valsechi, M. C. y Pereira, S. L. (2016). Do letramento aos letramentos: desafios na aproximação entre o letramento acadêmico e o letramento do professor. En A. B. Kleiman y J. A. Assis (Eds.), Significados e ressignificações do letramento: desdobramentos de uma perspectiva sociocultural sobre a escrita (pp. 27-59). Campinas: Mercado de Letras.

Vóvio, C. L. (2007a). Entre discursos: sentidos, práticas e identidades leitoras de alfabetizadores de jovens $e$ adultos. Tese de doutorado, Universidade Estadual de Campinas (UniCAMP), Campinas, sp, Brasil.

Vóvio, C. L. (2007b). Perfiles, prácticas y acervos de lectura de los educadores de adultos. Decisio (CREFAL), 16, 42-48.

Zavala, V. (2010). 'Quem está dizendo isso?' Letramento acadêmico, identidade e poder no ensino superior. En C. L. Vóvio, L. S. Sito, y P. B. de Grande, Letramentos: rupturas, deslocamentos e repercussóes de pesquisas em linguistica aplicada (pp. 71-95). Campinas, sP: Mercado de Letras.

How to reference this article: Kleiman, A. B. (2019). Literacidad e identidades en las investigaciones sobre formación docente en Brasil. Íkala, Revista de Lenguaje y Cultura, 24(2), 387-416. DoI: 10.17533/ udea.ikala.v24n02a11 